\title{
Friedreich's Ataxia Causes Redistribution of Iron, Copper, and Zinc in the Dentate Nucleus
}

\author{
Arnulf H. Koeppen • R. Liane Ramirez • Devin Yu • \\ Sarah E. Collins • Jiang Qian • Patrick J. Parsons • \\ Karl X. Yang • Zewu Chen • Joseph E. Mazurkiewicz • \\ Paul J. Feustel
}

Published online: 5 May 2012

(C) The Author(s) 2012. This article is published with open access at Springerlink.com

\begin{abstract}
Friedreich's ataxia (FRDA) causes selective atrophy of the large neurons of the dentate nucleus (DN). High iron $(\mathrm{Fe})$ concentration and failure to clear the metal from the affected brain tissue are potential risk factors in the progression of the lesion. The DN also contains relatively high amounts of copper $(\mathrm{Cu})$ and zinc $(\mathrm{Zn})$, but the importance of these metals in FRDA has not been established. This report describes nondestructive quantitative $\mathrm{X}$-ray fluorescence (XRF) and "mapping" of $\mathrm{Fe}, \mathrm{Cu}$, and $\mathrm{Zn}$ in polyethylene glycol-dimethylsulfoxide (PEG/DMSO)-embedded DN of 10 FRDA patients and 13 controls. Fe fluorescence arose predominantly from the hilar white matter, whereas $\mathrm{Cu}$ and $\mathrm{Zn}$ were present at peak levels in DN gray matter. Despite collapse of the DN in FRDA, the location of the peak Fe signal did not change. In contrast, the $\mathrm{Cu}$ and $\mathrm{Zn}$ regions broadened
\end{abstract}

Dedication This work is dedicated to the memory of the late Walter M. Gibson who guided his research team at X-Ray Optical Systems to establish X-ray fluorescence as a diagnostic tool in diseases of humans and animals.

A. H. Koeppen $(\bowtie) \cdot$ R. L. Ramirez $\cdot$ D. Yu $\cdot$ S. E. Collins

Research Service (151), Veterans Affairs Medical Center,

113 Holland Ave,

Albany, NY 12208, USA

e-mail: Arnulf.Koeppen@med.va.gov

A. H. Koeppen

Department of Neurology, Albany Medical College,

Albany, NY 12208, USA

A. H. Koeppen · J. Qian

Department of Pathology, Albany Medical College,

Albany, NY 12208, USA

P. J. Parsons $\cdot$ K. X. Yang

Laboratory of Inorganic and Nuclear Chemistry,

Wadsworth Center, New York State Department of Health

and Department of Environmental Health Sciences,

Albany, NY 12201, USA and overlapped extensively with the Fe-rich region. Maximal metal concentrations did not differ from normal (in micrograms per milliliter of solid $\mathrm{PEG} / \mathrm{DMSO}$ as means \pm S.D.): $\mathrm{Fe}$ normal, 364 \pm 117 , FRDA, 344 \pm 159 ; Cu normal, 33 \pm 13 , FRDA, 33 \pm 18 ; and Zn normal, $32 \pm 16$, FRDA, $33 \pm 19$. Tissues were recovered from PEG/DMSO and transferred into paraffin for matching with immunohistochemistry of neuronspecific enolase (NSE), glutamic acid decarboxylase (GAD), and ferritin. NSE and GAD reaction products confirmed neuronal atrophy and grumose degeneration that coincided with abnormally diffuse $\mathrm{Cu}$ and $\mathrm{Zn}$ zones. Ferritin immunohistochemistry matched Fe XRF maps, revealing the most abundant reaction product in oligodendroglia of the $\mathrm{DN}$ hilus. In FRDA, these cells were smaller and more numerous than normal. In the atrophic DN gray matter of FRDA, anti-ferritin labeled

P. J. Parsons $\cdot$ K. X. Yang

The University at Albany,

Albany, NY 12201, USA

Z. Chen

X-Ray Optical Systems,

East Greenbush, NY 12061, USA

J. E. Mazurkiewicz • P. J. Feustel

Center for Neuropharmacology and Neuroscience,

Albany Medical College,

Albany, NY 12208, USA 
mostly hypertrophic microglia. Immunohistochemistry and immunofluorescence of the $\mathrm{Cu}$-responsive proteins $\mathrm{Cu}, \mathrm{Zn}$ superoxide dismutase and $\mathrm{Cu}^{++}$-transporting ATPase $\alpha$ peptide did not detect specific responses to $\mathrm{Cu}$ redistribution in FRDA. In contrast, metallothionein (MT)-positive processes were more abundant than normal and contributed to the gliosis of the DN. The isoforms of MT, MT-1/2, and brain-specific MT-3 displayed only limited co-localization with glial fibrillary acidic protein. The results suggest that MT can provide effective protection against endogenous $\mathrm{Cu}$ and $\mathrm{Zn}$ toxicity in FRDA, similar to the neuroprotective sequestration of $\mathrm{Fe}$ in holoferritin.

Keywords $\mathrm{Cu}^{++}$-transporting ATPase $\alpha$-peptide (ATP7A, Menkes protein) $\cdot$ Copper $\cdot \mathrm{Cu}, \mathrm{Zn}$-superoxide dismutase . Dentate nucleus $\cdot$ Ferritin $\cdot$ Friedreich's ataxia $\cdot$ Iron . Metallothionein $\cdot \mathrm{X}$-ray fluorescence $\cdot$ Zinc

\section{Introduction}

In the vast majority of patients with Friedreich's ataxia (FRDA), the mutation consists of a homozygous guanineadenine-adenine (GAA) trinucleotide repeat expansion in the frataxin gene (chromosome 9q21). The normal gene product, frataxin, is critically important for the biogenesis of iron-sulfur clusters though the protein may have several other functions (review in ref. [1]). Among other lesions of the central and peripheral nervous systems, FRDA causes selective atrophy of the large neurons of the dentate nucleus (DN) [2]. Smaller nerve cells persist [2] and continue to provide GABA-ergic afferent terminals to the inferior olivary nuclei. In contrast, GABA-ergic corticonuclear connections that normally provide two thirds of synaptic terminals to the $\mathrm{DN}$, undergo grumose degeneration, and the overall synaptic density declines [3]. A recent systematic anatomical study established that loss of large DN neurons constitutes the only critical interruption of the "cerebellar module" in FRDA [2] and the main correlate to cerebellar ataxia in FRDA.

The DN normally contains abundant iron (Fe). Peculiarly, collapse of this gray matter structure in FRDA does not lead to a net decrease or increase of the metal when concentrations are determined on tissue digests [4]. The vulnerability of the DN to frataxin deficiency may or may not be related to its high Fe content. Several other gray matter structures, such as globus pallidus, subthalamic nucleus, red nucleus, and substantia nigra, are also Fe-rich but appear exempt from destruction in FRDA. To date, there is no direct evidence that $\mathrm{Fe}$ in the $\mathrm{DN}$ becomes toxic or that the lesion is due to an excess of reactive oxygen species. Nevertheless, many in vitro models of FRDA show great sensitivity to oxidative stress. Bayot et al. [5] recently summarized the evidence for the primary role of $\mathrm{Fe}$ in the pathogenesis of
FRDA and proposed that $\mathrm{Fe}$ accumulation in certain systems, including the human heart, is a secondary event. Though Fe may not be critical in the damage to large DN neurons, the metal may be important in downstream effects of the primary lesion. Koeppen et al. [4] documented changes in two Fe-responsive proteins of the DN, ferritin and ferroportin, by immunohistochemistry and analysis of ferritin subunits by Western blotting. The results suggested that $\mathrm{Fe}$ does not remain inert throughout the course of FRDA [4], implying the presence of ionic iron as a potential catalyst in the Fenton reaction.

The DN also contains two other metals with established physiological functions, namely, copper $(\mathrm{Cu})$ and zinc $(\mathrm{Zn})$. The concentrations of these metals are relatively high at 10 $15 \%$ of total $\mathrm{Fe}$ [6-9]. A prior synchrotron study of fixed unembedded slices of human cerebellum confirmed prominent fluorescence of $\mathrm{Fe}, \mathrm{Cu}$, and $\mathrm{Zn}$ in the $\mathrm{DN}$ but also showed that these metals are only partially co-localized [10]. In contrast to $\mathrm{Fe}$, the literature contains no information heretofore on the fate of $\mathrm{Cu}$ and $\mathrm{Zn}$ in the $\mathrm{DN}$ of patients with FRDA. Inappropriate release of endogenous $\mathrm{Cu}$ ions, and perhaps $\mathrm{Zn}$ ions, from $\mathrm{DN}$ neurons may contribute to oxidative injury. The combined effect of free $\mathrm{Fe}$ and $\mathrm{Cu}$ is perhaps more serious than that of either metal alone. The experimental intracerebral, intraventricular, or subarachnoid injection of inorganic $\mathrm{Cu}$ salts $[11,12]$ is very destructive, but no data are available regarding the cells that regulate the metal or the response of specific cuproproteins. The experimental intraventricular administration of an organic $\mathrm{Cu}$ compound, namely, $\mathrm{Cu}$-histidine, in an effort to explore potential replacement therapy in Menkes disease, also causes damage to the exposed brain surfaces [13].

This report presents qualitative and quantitative observations on the DN in FRDA that were gained through application of nondestructive X-radiation of tissue samples. Xray fluorescence (XRF) of $\mathrm{Fe}, \mathrm{Cu}$, and $\mathrm{Zn}$ was correlated with the histopathology of the DN. While ferritin is an excellent marker of $\mathrm{Fe}$ dysmetabolism, similar storage proteins for $\mathrm{Cu}$ and $\mathrm{Zn}$ do not exist. This effort also included the immunohistochemical examination of two cuproproteins that may "recognize" shifts in brain $\mathrm{Cu}$ levels, namely, $\mathrm{Cu}$, $\mathrm{Zn}$-superoxide dismutase (SOD) and $\mathrm{Cu}^{++}$-transporting ATPase $\alpha$-peptide (ATP7A, Menkes protein), and of three metallothionein isoforms.

\section{Material and Methods}

Tissue Samples and Embedding in Polyethylene Glycol 1450/Dimethylsulfoxide

Table 1 shows basic clinical and genetic information of 10 patients with FRDA from whom sufficient DN tissue was 
Table 1 Basic clinical information of 10 patients with FRDA

${ }^{\mathrm{a}}$ Mean \pm standard deviation and range

\begin{tabular}{llllll}
\hline $\begin{array}{l}\text { Patient no. } \\
\text { and sex }\end{array}$ & $\begin{array}{l}\text { Age of onset } \\
\text { (years) }\end{array}$ & $\begin{array}{l}\text { Age of death } \\
\text { (years) }\end{array}$ & $\begin{array}{l}\text { Disease duration } \\
\text { (years) }\end{array}$ & $\begin{array}{l}\text { GAA repeats } \\
\text { allele 1 }\end{array}$ & $\begin{array}{l}\text { GAA repeats } \\
\text { allele 2 }\end{array}$ \\
\hline FRDA 1, M & 10 & 24 & 14 & 1,050 & 700 \\
FRDA 2, M & 7 & 34 & 27 & 1,114 & 1,114 \\
FRDA 3, F & 17 & 50 & 34 & 1,122 & 515 \\
FRDA 4, F & 50 & 83 & 33 & 236 & 106 \\
FRDA 5, F & 18 & 63 & 45 & 730 & 639 \\
FRDA 6, F & 6 & 23 & 17 & 864 & 668 \\
FRDA 7, M & 9 & 33 & 24 & 925 & 925 \\
FRDA 8, M & 9 & 27 & 18 & 1,070 & 700 \\
FRDA 9, F & 15 & 69 & 54 & 560 & 560 \\
FRDA 10, M & 25 & 67 & 42 & 160 & 160 \\
& $16.6 \pm 13.1^{\mathrm{a}}$ & $47.3 \pm 21.9$ & $30.8 \pm 13.2$ & $783 \pm 357$ & $609 \pm 306$ \\
& $(6-50)$ & $(24-83)$ & $(14-54)$ & $(160-1,122)$ & $(106-1,114)$ \\
\hline
\end{tabular}

available for embedding in polyethylene glycol 1450/dimethylsulfoxide (PEG/DMSO) and examination by XRF. Control samples came from 13 persons (3 women, 10 men) who died without evidence of central nervous system disease. Mean age of death in years and standard deviation were $68.7 \pm 10.5$ (range 50-85 years). The authors received approval from the Institutional Review Board at the Veterans Affairs Medical Center in Albany, NY, USA, for research on autopsy tissues obtained from human subjects.

Fixed pieces of cerebellar hemisphere with distinctly visible DN were progressively infiltrated by PEG (Sigma, St. Louis, MO, USA) as described before [14, 15]. Water and fixative in the tissue samples were replaced at room temperature by immersion in PEG 400 at increasingly higher concentrations (30-90\% by volume), followed by PEG 1000 and PEG 1450/DMSO at $60^{\circ} \mathrm{C}$. After cooling, the tissue blocks were "faced" in a microtome to present a smooth surface for the measurements of $\mathrm{Fe}, \mathrm{Cu}$, and $\mathrm{Zn}$ by XRF. Care was taken to prevent metal contamination by use of Teflon-coated microtome blades (Sturkey, Lebanon, PA, USA).

\section{Monochromatic XRF Instrumentation}

A custom-built XRF mapping instrument was assembled by X-Ray Optical Systems (XOS, East Greenbush, NY, USA) specifically for use in this study and optimized for imaging $\mathrm{Fe}, \mathrm{Cu}$, and $\mathrm{Zn}$ distributions in PEG/DMSO-embedded tissue blocks. Chen et al. [16] and Gibson et al. [17] have published theory and practical application of nondestructive XRF. Hardware components include a $50-\mathrm{kV}, 1-\mathrm{mA}$, molybdenum target $\mathrm{X}$-ray source, generating a monochromatic beam through a doubly curved crystal optic (DCC) [18]; a motion controller with an $x-y$ scanning mechanism; and a silicon drift detector (SDD). Specimens are mounted in a custom-designed holder that aligns the faced surface in a perfectly horizontal position. The instrument contains a small camera that allows the user to define the region on standards or specimens that are to be scanned. Multiple specimens can be scanned sequentially. The X-ray beam travels in a raster-like manner across the user-defined region of the samples, and $\mathrm{Fe}, \mathrm{Cu}$, and $\mathrm{Zn}$ fluorescent photons are detected and counted by the SDD. Step widths and exposure times can also be controlled by the operator. For this investigation, these parameters were set at $0.1 \mathrm{~mm}$ and $5 \mathrm{~s}$, respectively. The source beam coupled with the DCC optic generates an elliptical spot of radiation that varies with the distance of the delivery optics from the surface of the specimen (the $z$-axis). In a typical application, it measures $100 \times 240 \mu \mathrm{m}\left(18,849 \mu \mathrm{m}^{2} \approx 0.02 \mathrm{~mm}^{2}\right)$. The unit can be operated at room temperature without the need for a vacuum and has an overall power consumption of $350 \mathrm{~W}$. The software application is a Windows-based computer program that generates two-dimensional images or "maps" of metal distribution, with X-ray intensity represented on the $z$-axis as a color-coded scale. XRF signals are recorded as counts $/ 5 \mathrm{~s}$, and signal intensity is directly proportional to metal concentration (Fig. 1).

Calibration Strategy for Quantitative Measurements by XRF

Calibration standards for $\mathrm{Fe}, \mathrm{Cu}$, and $\mathrm{Zn}$ were prepared from pure compounds of each element, in which the metal ion is chelated by a porphyrin ring. Fe-III-, Cu-II-, and Zn-IImesoporphyrins were purchased from Frontier Scientific, Logan, UT, USA. A known mass of each material was weighed out and the metal content estimated on the molecular formula of each compound, the relative atomic mass of each metal, and the known relative mass of the metalloporphyrin. The target concentrations of $\mathrm{Fe}, \mathrm{Cu}$, and $\mathrm{Zn}$ were estimated to be 600,100 , and $100 \mu \mathrm{g} / \mathrm{ml}$, respectively. The metalloporphyrins were first dissolved in DMSO (Sigma, 
$\mathrm{Fe}$

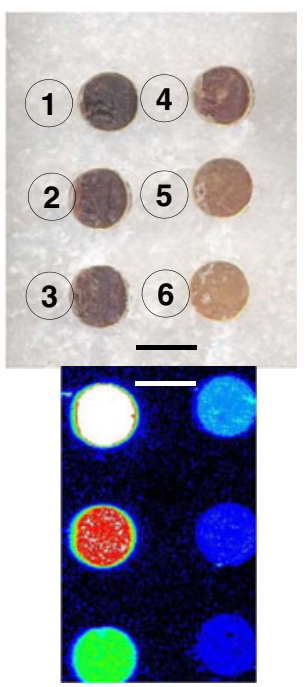

Fe fluorescence

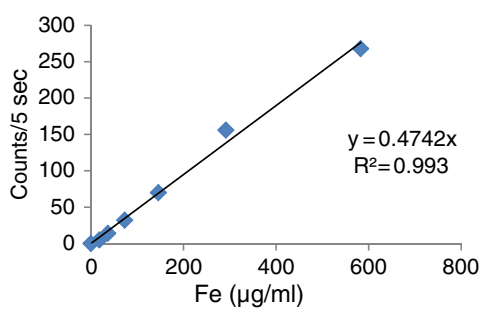

$\mathrm{Cu}$

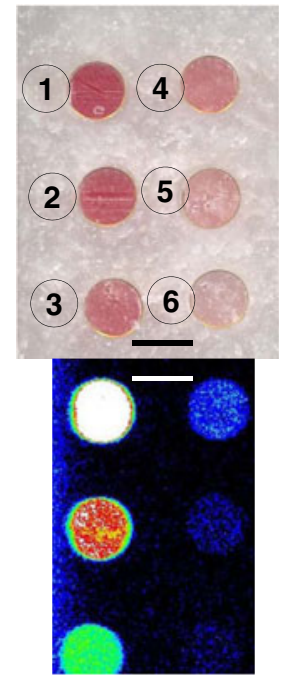

Cu fluorescence

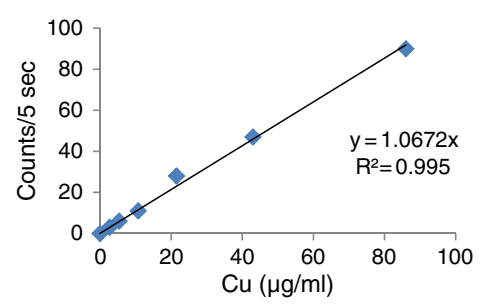

$\mathrm{Zn}$

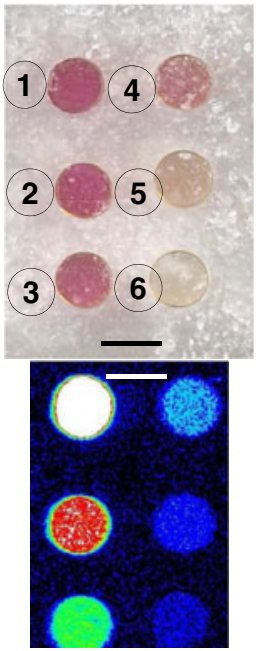

Zn fluorescence

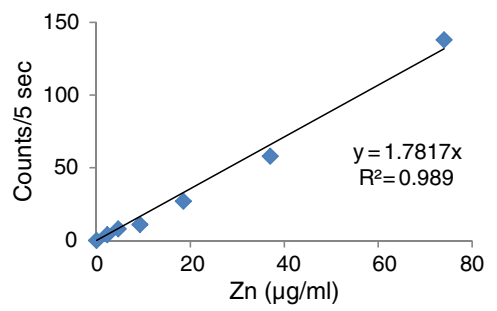

Fig. $1 \mathrm{Fe}, \mathrm{Cu}$, and $\mathrm{Zn}$ standards. Top panel: Congealed solutions of Fe-III-, Cu-II-, and Zn-II-mesoporphyrins in gelatin capsules. The highest concentrations are present in (1) of each standard. After dilution, the concentrations range, in micrograms per milliliter, from 620 to 19.375 for $\mathrm{Fe}$; 86 to 2.688 for $\mathrm{Cu}$; and 74 to 3.125 for $\mathrm{Zn}$. Middle panel: Matching XRF maps of the standards shown in the top panel. Pseudocolors indicate the declining concentration from maximum (white) to red, green, light blue, and dark blue. Bottom panel: Regression analysis of $\mathrm{Fe}, \mathrm{Cu}$, and $\mathrm{Zn}$. Ten point-measurements were made of each standard concentration and averaged. The mean values were reduced by background XRF that was obtained by sampling the block outside the capsules. The goodness of fit is given by $R^{2}$ values. Bars in top and middle panels represent $5 \mathrm{~mm}$
St. Louis, MO, USA). Hot liquid PEG $1450\left(60^{\circ} \mathrm{C}\right)$ was then added to achieve a DMSO concentration of $10 \%$. A dilutional series was prepared by the addition of the liquid PEG/ DMSO mixture, and each successive concentration of metal represented one half of the preceding mixture. Six equally spaced circular openings were made in a blank PEG/DMSO block with the aid of a 5-mm-wide cork borer (Fig. 1). The longer portions of no. 3 gelatin capsules (Star West Botanicals, Rancho Cordova, CA, USA; approximate volume, $450 \mu \mathrm{l})$ were then inserted to receive the hot solutions of serially diluted metalloporphyrins (about $400 \mu \mathrm{l}$; Fig. 1). The liquid transmitted sufficient heat to temporarily melt the surrounding solid PEG and provide a tight seal after cooling. After the PEG/DMSO mixtures became solid, capsules and surrounding block were faced as described above for tissue samples.

The exact concentrations of $\mathrm{Fe}, \mathrm{Cu}$, and $\mathrm{Zn}$ of the PEGembedded XRF calibration standards were determined independently using another analytical technique. Briefly, separate gelatin capsules were prepared in which $100 \mu$ of each of the metalloporphyrins in PEG/DMSO (the highest standard concentration) and unspiked PEG/DMSO (the calibration blank) were analyzed for $\mathrm{Fe}, \mathrm{Cu}$, and $\mathrm{Zn}$ by the Laboratory of Inorganic and Nuclear Chemistry at Wadsworth Center, New York State Department of Health. Each capsule was digested in concentrated nitric acid, hydrogen peroxide, and concentrated hydrochloric acid on a hot block using an established procedure. After appropriate dilution, $\mathrm{Fe}, \mathrm{Cu}$, and $\mathrm{Zn}$ were determined in the digest by inductively coupled plasmaoptical emission spectrometry. The found values for $\mathrm{Fe}, \mathrm{Cu}$, and $\mathrm{Zn}$ in micrograms per milliliter of PEG/DMSO were 620, 86 , and 74 , respectively, and yielded six-point linear calibration curves (Fig. 1). Detection limits, in micrograms per milliliter (or parts per million), are 4 for $\mathrm{Fe}, 1$ for $\mathrm{Cu}$, and 1 for $\mathrm{Zn}$.

Each run included the prepared $\mathrm{Fe}, \mathrm{Cu}$, and $\mathrm{Zn}$ standards and up to four tissue blocks containing DN from FRDA patients or controls. The regions of PEG/DMSO between 
the calibration standards (Fig. 1) and just outside the visible tissue samples served as blanks. Maps obtained from tissue samples were used to compare the localization of metals. In a typical run, signal strengths were divided into six intervals, ranging from background to maximum $\mathrm{XRF}$ count rate. This process generated six distinct "zones" of XRF intensity within the arbitrary interval limits that were indicated by six separate colors. In order of declining XRF strength, these colors were white, red, orange, green, light blue, and dark blue. Ten points in each zone were analyzed for $\mathrm{Fe}, \mathrm{Cu}$, and $\mathrm{Zn}$ content. The average count rate (counts $/ 5 \mathrm{~s}$ ) was corrected by subtracting the mean background signal, and the corrected XRF was used to quantify $\mathrm{Fe}, \mathrm{Cu}$, and $\mathrm{Zn}$ based on the respective calibration curves (Fig. 1).

\section{Tissue Recovery from PEG/DMSO}

After XRF mapping and signal quantification were complete, the tissue blocks were immersed in phosphatebuffered saline (PBS), and PEG/DMSO was completely removed through several changes of PBS. The recovered tissues were then suspended overnight in sodium phosphatebuffered $4 \%$ paraformaldehyde prior to embedding into paraffin by standard procedures.

Immunohistochemistry, Immunofluorescence, and Lectin Affinity Fluorescence

Six micrometer-thick paraffin sections were stained by hematoxylin and eosin to exclude specimens with siderocalcinosis of the DN. Monoclonal or polyclonal antibodies to the following proteins were used for immunohistochemistry or immunofluorescence: neuron-specific enolase (NSE; mouse monoclonal; Chemicon, Temecula, CA, USA); glutamic acid decarboxylase (GAD; mouse monoclonal; MBL International, Woburn, MA, USA); ferritin (rabbit polyclonal; DAKO, Carpinteria, CA, USA; goat polyclonal, GenWay, San Diego, CA, USA); SOD (rabbit polyclonal; Sigma-Aldrich, St. Louis, MO, USA); ATP7A (rabbit polyclonal; Bioworld Technology, St. Louis Park, MN, USA); metallothioneins 1 and 2 (MT-1/2) (mouse monoclonal; Invitrogen, Frederick, MD, USA); metallothionein-3 (MT-3) (rabbit polyclonal; Sigma-Aldrich, St. Louis, MO, USA); glial fibrillary acidic protein (mouse monoclonal, Sternberger Monoclonals-Covance, Princeton, NJ, USA; and rabbit polyclonal, DAKO); and CD68 (monoclonal, Santa Cruz Biotechnology, Santa Cruz, CA, USA). The immunohistochemical protocol was similar to previously published techniques [2, 15]. Antigen retrieval methods were DIVA (a proprietary name for a decloaking solution sold by Biocare Medical, Concord, CA, USA) for NSE, GAD, glial fibrillary acidic protein (GFAP), ferritin, and the metallothioneins or incubation in $0.1 \mathrm{M}$ citric acid/sodium citrate buffer $\left(\mathrm{pH}\right.$ 6) for $15 \mathrm{~min}$ at $95^{\circ} \mathrm{C}$ for SOD, ATP7A, and CD68. Fluorophore-labeled secondary antibodies (Cy3 and Alexa488) were purchased from Jackson ImmunoResearch, West Grove, PA, USA. Biotinylated secondary antibodies and fluorescein isothiocyanate (FITC)-labeled streptavidin came from Vector Labs., Burlingame, CA, USA. Horseradish peroxidase-labeled streptavidin was purchased from Sigma-Aldrich, St. Louis, MO, USA.

Co-localization of SOD in ferritin-reactive cells of the DN was examined by double-label immunofluorescence with the goat polyclonal antibody to human ferritin and the rabbit polyclonal anti-SOD antibody. The technique was similar to a previously described method [4] though the blocking solution used here was $10 \%$ normal donkey serum in PBS and antibodies were diluted in $1 \%$ donkey serum. Chelation and antigen retrieval with DIVA were identical to the immunohistochemical protocol for the visualization of ferritin. After incubation with anti-ferritin, the affixed antibody was detected with Cy3-labeled donkey anti-goat IgG. After washing and additional suppression, SOD was visualized by the sequence: rabbit polyclonal anti-SOD $\rightarrow$ biotinylated anti-rabbit IgG $\rightarrow$ FITC-labeled streptavidin. Co-localization of SOD and CD68-positive microglia in the DN was determined by the following sequence: mouse monoclonal anti-CD68 $\rightarrow$ donkey Cy3labeled anti-mouse IgG $\rightarrow$ rabbit anti-SOD $\rightarrow$ Alexa488labeled anti-rabbit IgG. Images were analyzed in a Zeiss LSM 510 Meta confocal microscope with a PlanApo $63 \mathrm{X}$ oil immersion objective and a numerical aperture of 1.4. Exciting wavelengths alternated between 488 and $543 \mathrm{~nm}$, and the images were collected through band pass (BP) filters of $500-530 \mathrm{~nm}$ for FITC and Alexa488 and $565-615 \mathrm{~nm}$ for $\mathrm{Cy} 3$.

The localization of ATP7A in vessel walls was based on lectin affinity cytochemistry with tetramethylrhodamine isothiocyanate (TRITC)-labeled Ricinus communis agglutinin 1 (RCA-1) (Vector) after immunofluorescence with polyclonal anti-ATP7A had been completed through the series of biotinylated anti-rabbit IgG and FITC-streptavidin. The labeled lectin was diluted in $0.05 \mathrm{M}$ Tris buffer $\mathrm{pH} 7.6$, containing $1 \mathrm{mM} \mathrm{CaCl}_{2}$, and applied at room temperature for $1 \mathrm{~h}$. The sections were washed in the same $\mathrm{CaCl}_{2}$ containing buffer and then mounted with the same buffer containing $50 \%$ glycerol (by volume). For visualization, the BP filters were set at $500-530 \mathrm{~nm}$ for FITC and 565 $615 \mathrm{~nm}$ for TRITC.

Visualization of MT-1/2 and MT-3, and GFAP, by doublelabel immunofluorescence varied with the nature of the primary antibodies. For MT-1/2, detectable by a mouse monoclonal antibody, the sequence was (washing and blocking steps omitted): monoclonal anti-MT-1/2 $\rightarrow$ Alexa488-labeled donkey anti-mouse IgG $\rightarrow$ rabbit polyclonal anti-GFAP $\rightarrow$ Cy3-labeled donkey anti-rabbit IgG. For MT-3, detectable 
Table 2 Iron, copper, and zinc levels in the DN of 10 FRDA patients and 13 normal controls

\begin{tabular}{|c|c|c|c|c|c|c|}
\hline \multirow[t]{2}{*}{ Specimens } & \multicolumn{6}{|l|}{ Zones } \\
\hline & White & Red & Orange & Green & Light blue & Dark Blue \\
\hline \multicolumn{7}{|l|}{ Iron } \\
\hline FRDA & $344 \pm 159$ & $276 \pm 134$ & $219 \pm 101$ & $160 \pm 75$ & $86 \pm 35$ & $42 \pm 18$ \\
\hline Normal & $364 \pm 117$ & $297 \pm 108$ & $242 \pm 85$ & $178 \pm 55$ & $102 \pm 33$ & $55 \pm 15$ \\
\hline \multicolumn{7}{|l|}{ Copper } \\
\hline FRDA & $33 \pm 18$ & $24 \pm 13$ & $18 \pm 10$ & $14 \pm 8$ & $13 \pm 5$ & $12 \pm 4$ \\
\hline Normal & $33 \pm 13$ & $24 \pm 10$ & $18 \pm 9$ & $14 \pm 7$ & $7 \pm 5$ & - \\
\hline \multicolumn{7}{|l|}{ Zinc } \\
\hline FRDA & $33 \pm 19$ & $26 \pm 16$ & $21 \pm 13$ & $16 \pm 10$ & $13 \pm 5$ & $5 \pm 1$ \\
\hline Normal & $32 \pm 16$ & $23 \pm 8$ & $18 \pm 7$ & $13 \pm 6$ & - & - \\
\hline
\end{tabular}

Results are expressed as micrograms per milliliter PEG/DMSO (mean \pm standard deviation). The computer program rendered maps based on interquartile range. Metal maps were segmented into six zones of different color to allow a more detailed assessment of concentration gradients. White represents maximum XRF. Red, orange, green, light blue, and dark blue represent zones of progressively lower XRF intensity. In some specimens, the computer program did not resolve light and dark blue zones due to insufficient copper or zinc XRF

by a polyclonal antibody, the sequence was: monoclonal anti-GFAP $\rightarrow$ Cy3-labed anti-mouse IgG $\rightarrow$ polyclonal anti-MT-3 $\rightarrow$ Alexa488-labeled anti-rabbit IgG. The filter settings were as listed above for FITC/Alexa488 and Cy3.

\section{Statistical Analysis}

Differences in mean $\mathrm{Fe}, \mathrm{Cu}$, and $\mathrm{Zn}$ concentrations in all six-color zones were analyzed by standard $t$ test, assuming equal variance (Table 2). The following method was used to determine the abnormal admixture of copper and iron in the DN of FRDA: The Fe map of each case or control was displayed on a computer screen and segmented into six zones as described above. Regions of maximum Fe XRF were outlined on a superimposed clear plastic sheet that was placed over the computer screen, and Fe signals were collected from 25 randomly selected points. While the plastic sheet remained in place, Fe maps were exchanged by $\mathrm{Cu}$
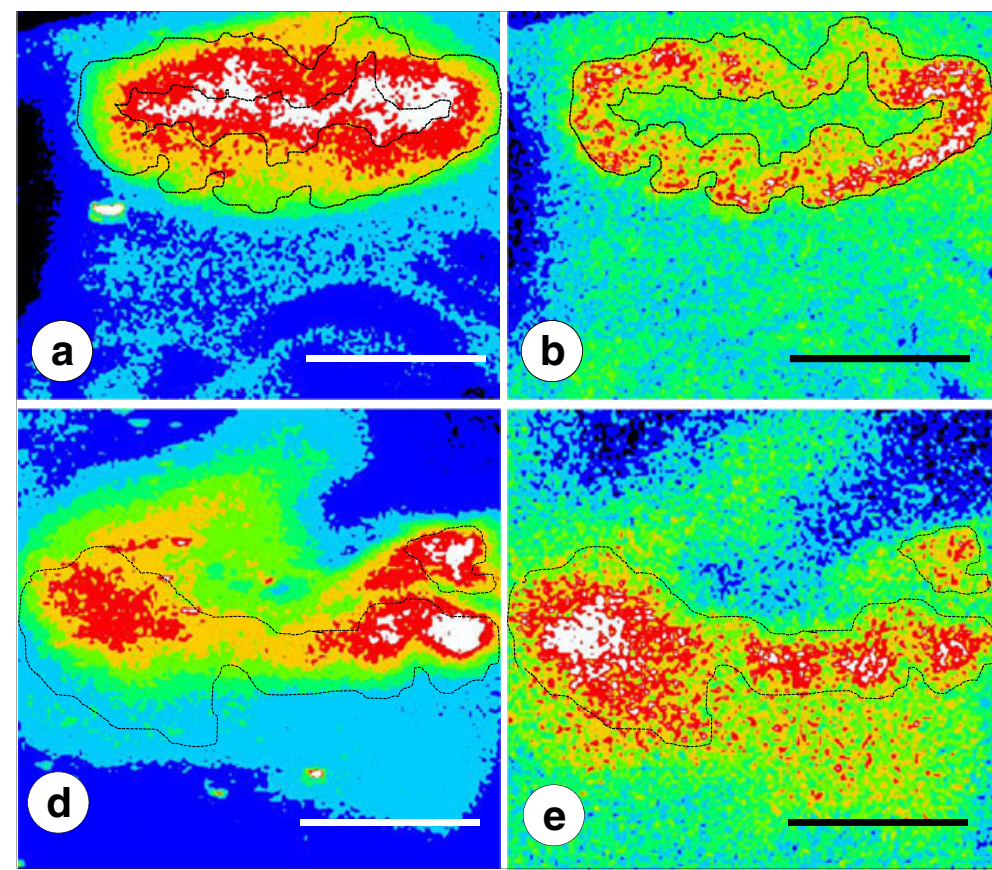

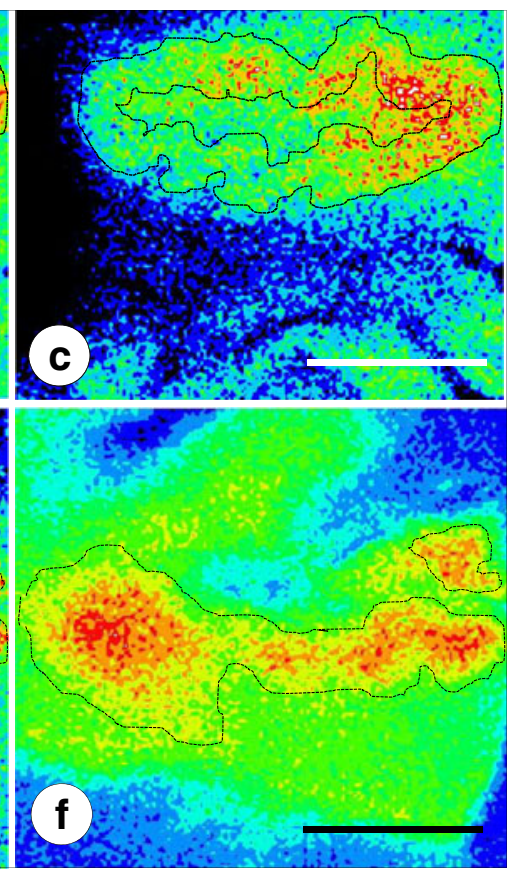

Fig. 2 XRF maps of the DN in a normal control and a case of FRDA. a-c normal; $\mathbf{d}-\mathbf{f}$ FRDA. The outlines of the $\mathrm{Cu}$ maps with peak signals $(\mathbf{b}, \mathbf{e})$ were transferred to the matching $\mathrm{Fe}$ and $\mathrm{Zn}$ maps. In the normal control $(\mathbf{a}-\mathbf{c})$, zones of maximum $\mathrm{Cu}$ and $\mathrm{Zn}$ are clearly demarcated from the peak Fe map (white). In FRDA (case FRDA5 F in Table 1), the normal ribbon-like $\mathrm{Cu}$ map has been replaced by several coalescing fields (e) that show extensive overlap with the peak Fe map (d). The distribution of $\mathrm{Zn}$ remains similar to that of $\mathrm{Cu}$. Bars, $5 \mathrm{~mm}$ 
maps, and $\mathrm{Cu}$ signals were collected from the same field. Concentrations of $\mathrm{Cu}$ and $\mathrm{Fe}$ were determined as described above. For each case or control, a mean $\mathrm{Cu} / \mathrm{Fe}$ ratio was calculated from the 25 data points. Mean $\mathrm{Cu} / \mathrm{Fe}$ ratios of the 10 FRDA patients and 13 controls were analyzed for statistically significant differences by standard $t$ test. A significance level of $\alpha=0.05$ was used for all analyses and comparisons.

\section{Results}

Figure 1 shows the encapsulated metalloporphyrin standards in PEG/DMSO blocks, the matching $\mathrm{Fe}, \mathrm{Cu}$, and $\mathrm{Zn} \mathrm{XRF}$ maps, and examples of regression analysis of XRF in counts $/ 5 \mathrm{~s}$ as a function of metal concentrations. Figure 2 illustrates $\mathrm{Fe}, \mathrm{Cu}$, and $\mathrm{Zn}$ maps of the $\mathrm{DN}$ in a normal control and a case of FRDA. Despite the obvious collapse of the DN in FRDA, the signals of $\mathrm{Fe}, \mathrm{Cu}$, and $\mathrm{Zn}$ persist. In the control specimen, Fe XRF is at a maximum in the center of the DN (mean in micrograms per milliliter \pm S.D., $346 \pm$ 117 ) and declines in a gradient toward the gray matter ribbon and the surrounding white matter (Fig. 2a). In the same tissue block, the strongest $\mathrm{Cu}$ and $\mathrm{Zn}$ signals arise from a relatively narrow ribbon that corresponds to the gray matter of the nucleus (Fig. 2b, c). In the normal DN, regions of maximum $\mathrm{Fe}$ are demarcated from the $\mathrm{Cu}$ and $\mathrm{Zn}$ regions. In contrast, the DN in FRDA displays a widening of the $\mathrm{Cu}$ and $\mathrm{Zn}$ zones and extensive overlap with the region of maximum $\mathrm{Fe}$ XRF (Fig. 2d-f). In fields of maximal $\mathrm{Fe}$ $\mathrm{XRF}$ (white), the mean $\mathrm{Cu} / \mathrm{Fe}$ ratio and standard deviation in normal controls $(0.046 \pm 0.012)$ are statistically significant
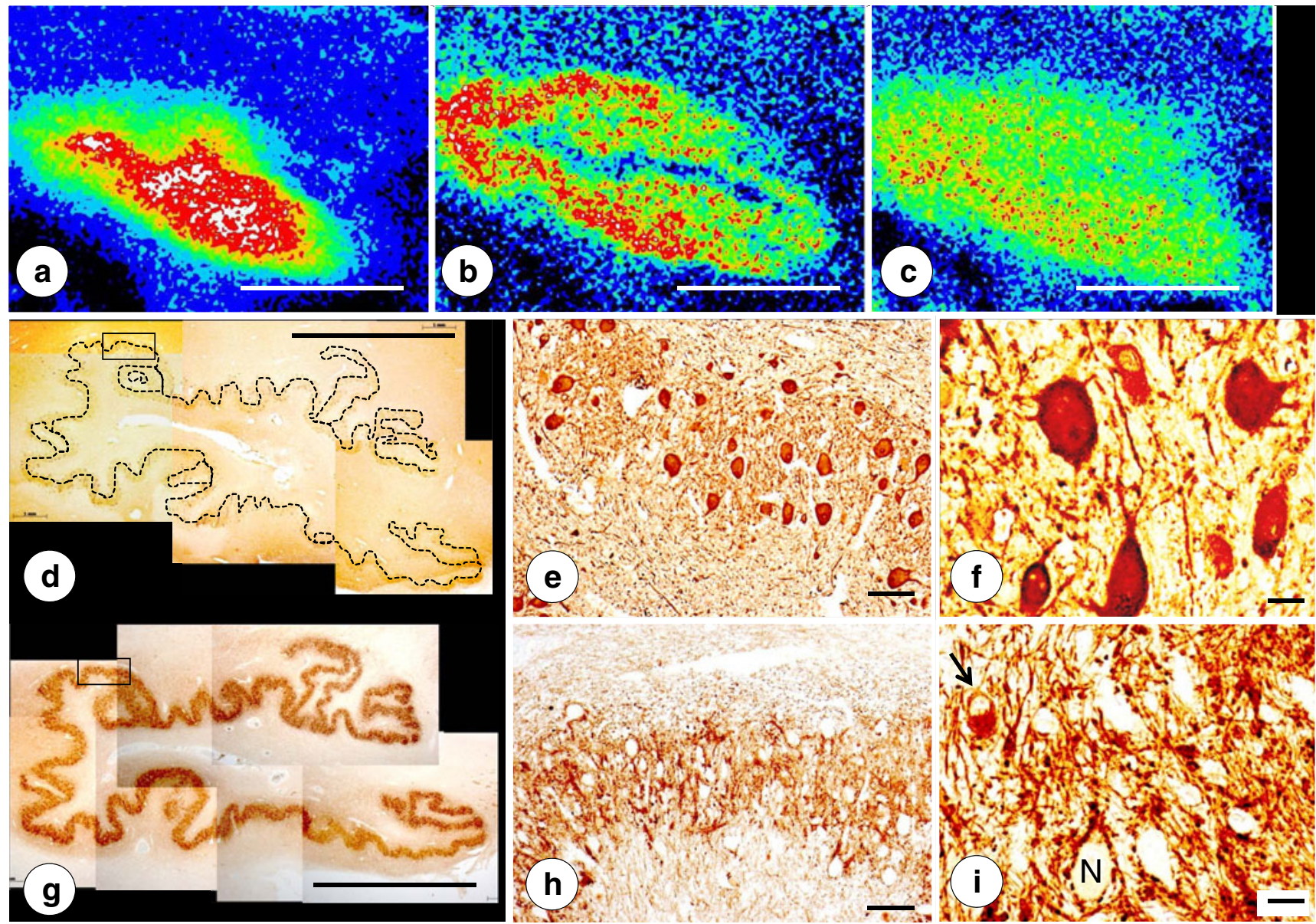

Fig. $3 \mathrm{Fe}, \mathrm{Cu}$, and $\mathrm{Zn} \mathrm{XRF}$ maps of a normal $\mathrm{DN}$ and matching sections after recovery from PEG/DMSO. a Fe XRF; b Cu XRF; c Zn XRF. d-f Immunohistochemistry of NSE; $\mathbf{g}-\mathbf{i}$ Immunohistochemistry of GAD. For clarity, the low-power composite of the DN gray matter ribbon in $\mathbf{d}$ was outlined by an interrupted line. The microphotographs in $\mathbf{e}$ and $\mathbf{h}$ correspond to the regions indicated by the rectangles in $\mathbf{d}$ and $\mathbf{g}$, respectively. The XRF maps confirm the differential localization of $\mathrm{Fe}, \mathrm{Cu}$, and $\mathrm{Zn}$. The $\mathrm{DN}$ gray matter ribbon, as shown by NSE (d) and GAD reaction products (g), matches the

distribution of maximum $\mathrm{Cu}(\mathbf{b})$ and $\mathrm{Zn}(\mathbf{c})$, whereas Fe XRF places the bulk of $\mathrm{Fe}$ into the central white matter of the DN (a). Both immunohistochemical stains show the normal thickness of DN gray matter $(250-300 \mu \mathrm{m})$. NSE reaction product visualizes large and small neurons of the normal DN (e-f). GAD reaction product labels axosomatic and axodendritic terminals, yielding negative images of DN nerve cells $(\mathbf{h}-\mathbf{i})$. The arrow in i points to a small neuron with GAD immunoreactivity in its cytoplasm. $N$, negative image of a neuron. Bars, a-d and g $5 \mathrm{~mm}$; e, h $100 \mu \mathrm{m} ; \mathbf{f}$, i $20 \mu \mathrm{m}$ 
$(p=0.04)$ from FRDA $(0.058 \pm 0.016)$. This data reflect a significant increase of $\mathrm{Cu}$ from 4.6 to $5.8 \%$ of $\mathrm{Fe}$ in the same zone.

Table 2 shows the quantification of $\mathrm{Fe}, \mathrm{Cu}$, and $\mathrm{Zn}$ in sixcolored zones along a concentration gradient within the $\mathrm{DN}$. Mean concentrations in FRDA do not differ significantly from the normal state.

Figure 3 presents the alignment of $\mathrm{Fe}, \mathrm{Cu}$, and $\mathrm{Zn}$ maps with stained sections after transfer of the PEG/ DMSO-infiltrated tissue blocks into paraffin. The $\mathrm{Cu}$ map (Fig. 3b) matches the major turns of the DN gray matter ribbon as revealed by NSE (Fig. 3d) and GAD immunohistochemistry (Fig. 3g). At higher magnifications of a defined region, the immunohistochemical stains reveal the normal neuropil of the DN (Fig. 3e, f, h, and i), including a small GABA-ergic neuron (Fig. 3i, arrow). A similarly processed specimen from a patient with FRDA is illustrated in Fig. 4. While still recognizable on the immunohistochemical stains of NSE and GAD, the greatly thinned gray matter ribbon of the DN now coincides with a much more diffuse $\mathrm{Cu}$ and $\mathrm{Zn}$ distribution (Fig. 4b, c). The stains for NSE (Fig. 4d-f) and GAD (Fig. $4 \mathrm{~g}-\mathrm{i}$ ) of the outlined area of the DN gray matter reveal loss of large nerve cells (Fig. 4e, f) and grumose degeneration of the DN (Fig. 4h, i). NSE (Fig. 4f) and GAD (Fig. 4i) reaction products confirm the preservation of small neurons in the DN. Cytoplasmic GAD reactivity of one small nerve cell reveals its GABAergic nature (Fig. 4i, arrow).

Figure 5 illustrates ferritin in the gray matter of the normal DN (Fig. 5a, b) and the DN of FRDA (Fig. 5c, d). Reaction product occurs mostly in microglia though some of the juxtaneuronal cells may be oligodendroglia (Fig. 5a).
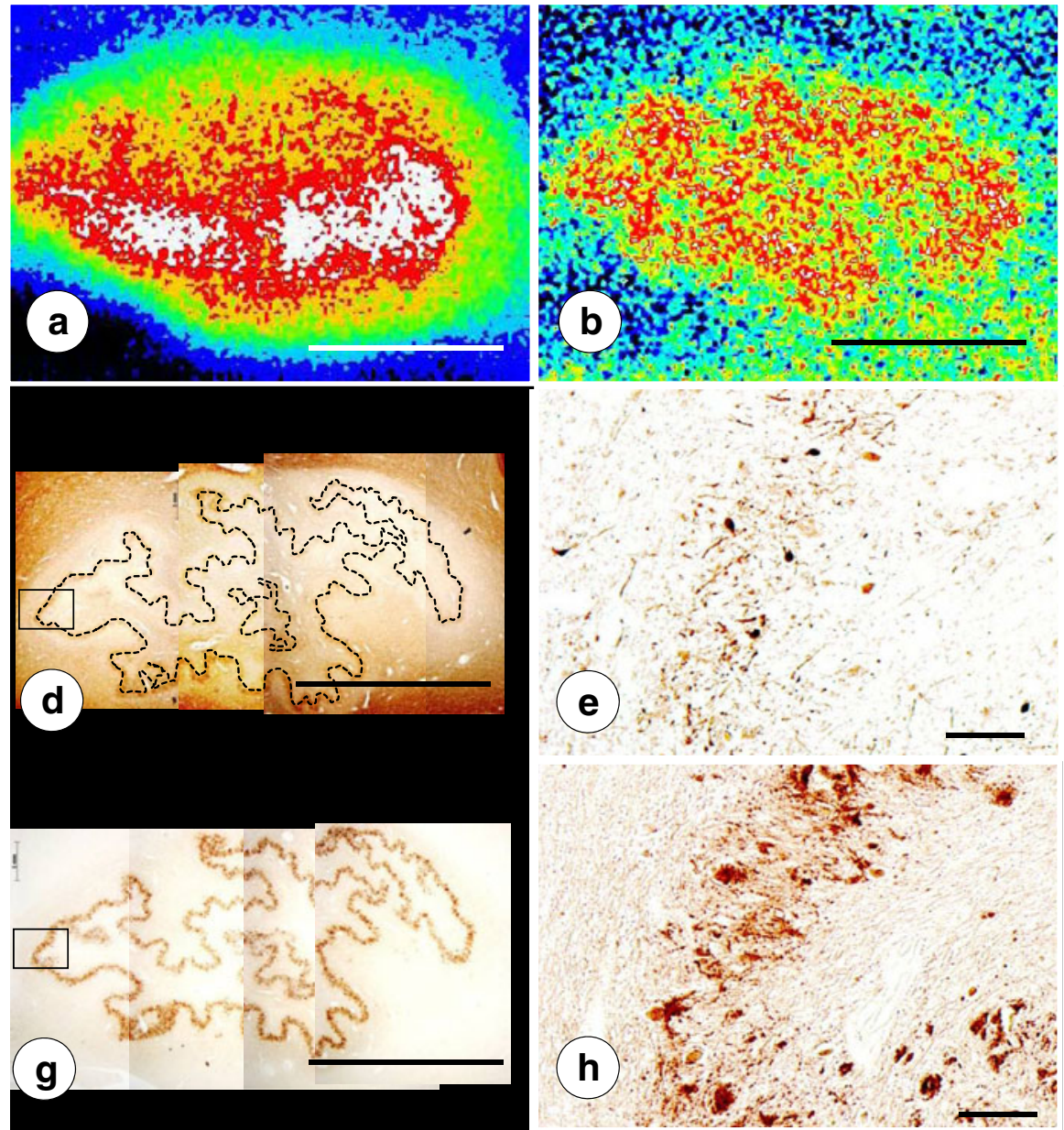

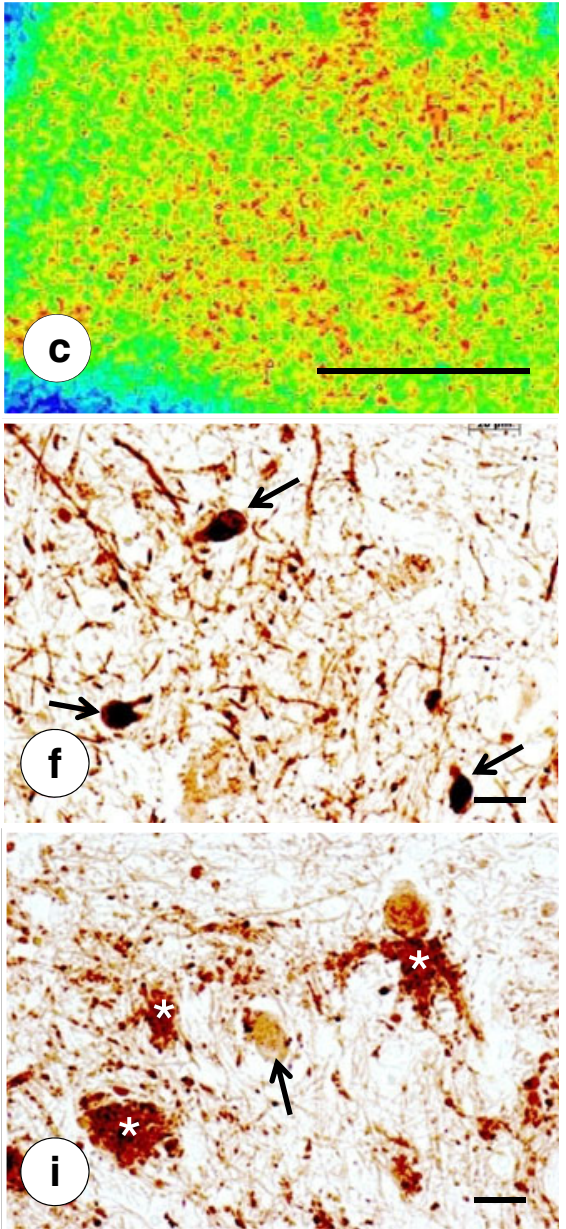

Fig. $4 \mathrm{Fe}, \mathrm{Cu}$, and $\mathrm{Zn}$ XRF maps of a DN in FRDA and matching sections after recovery from PEG/DMSO. a Fe XRF; b Cu XRF; c Zn XRF. $\mathbf{d}-\mathbf{f}$ Immunohistochemistry of NSE; $\mathbf{g}-\mathbf{i}$ Immunohistochemistry of GAD. For clarity, the low-power composite of the DN gray matter ribbon in $\mathbf{d}$ was outlined by an interrupted line. The microphotographs in $\mathbf{e}$ and $\mathbf{h}$ correspond to the regions indicated by the rectangles in $\mathbf{d}$ and $\mathbf{g}$, respectively. Regions of maximal XRF for $\mathrm{Fe}(\mathbf{a}), \mathrm{Cu}(\mathbf{b})$, and $\mathrm{Zn}$ (c) show extensive overlap. Higher magnification confirms thinning of the DN to $100-120 \mu \mathrm{m}$ and loss of large neurons (e, h). Small neurons are present in normal abundance (arrows in $\mathbf{f}$ ). Atrophy of the DN gray matter is also evident following GAD immunohistochemistry $(\mathbf{g}-\mathbf{i})$. Negative images of large neurons are absent, but grumose degeneration retains GAD immunoreactivity (white asterisks in i). The arrow in $\mathbf{i}$ indicates a small intact GABA-ergic neuron with cytoplasmic GAD reaction product. Images derived from patient FRDA3, F in Table 1. Bars: a-d, g 5 mm; e, h $100 \mu \mathrm{m}$; f, i $20 \mu \mathrm{m}$ 


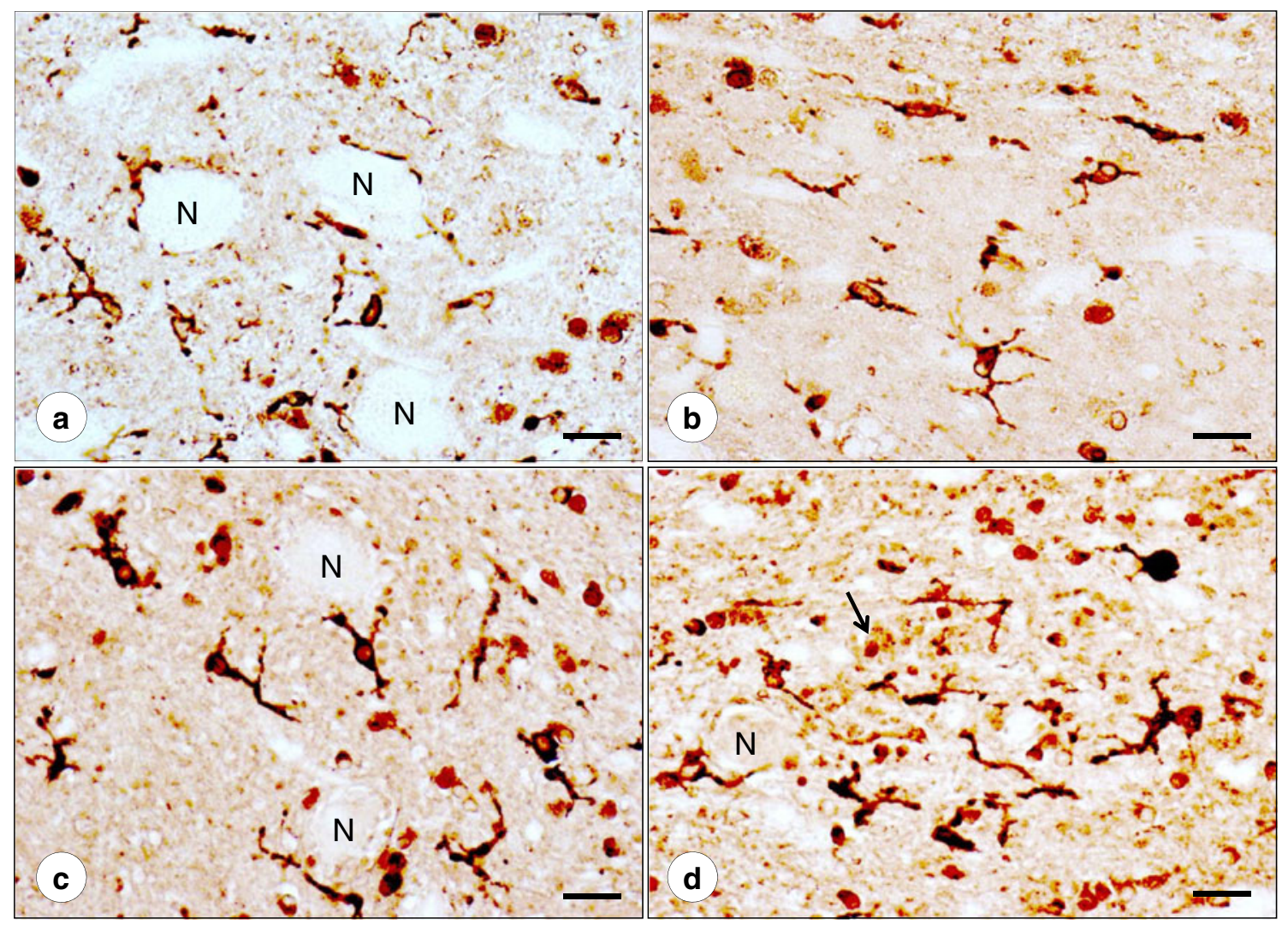

Fig. 5 Ferritin immunohistochemistry of DN gray matter. a, b Normal control; c, d FRDA (case FRDA1, M in Table 1). In the normal DN gray matter, reaction product labels cells with the morphology of microglia (a, b) though the juxtaneuronal ferritin-positive cells in a may represent oligodendroglia [4]. At the junction to the hilar white matter (b), ferritin-positive cells are all microglia. In FRDA, ferritin- reactive microglia are larger (c) and more frequent about grumose degeneration (d). The arrow in $\mathbf{d}$ points toward grumose degeneration that also contains ferritin reaction product. The parent neuron of the dendrites surrounded by grumose degeneration is located to the left. $N$, negative images of neuronal cell bodies; bars, $20 \mu \mathrm{m}$

image of a typical white matter oligodendrocyte adjacent to an SOD-positive cell. SOD-immunoreactive cells may be slightly more abundant around zones of grumose degeneration in FRDA (Fig. 7d).

Figure 8 confirms co-localization of SOD with cytosolic ferritin and CD68 in DN gray matter, supporting the identification of SOD-positive cells as microglia. All SODpositive microglia contain ferritin and CD68 reaction products though not all ferritin- and CD68-reactive cells contain SOD. The abundant CD68 reaction product in the cell illustrated in Fig. 8k suggests microglial hypertrophy in FRDA that is also apparent by positive-contrast immunohistochemistry of ferritin (Fig. $5 \mathrm{c}$ ). The strongly reactive oligodendroglia of the DN white matter (Fig. 6) are SODnegative (not illustrated). In a separate double-label immunofluorescence procedure with anti-SOD and anti-GFAP, SOD-reactive cells were GFAP-negative, militating against the presence of the enzyme in astrocytes (not illustrated).

Figure 9 shows ATP7A protein by positive-contrast immunohistochemistry and in combined immunofluorescence with RCA-1 lectin affinity fluorescence. In DN gray and (Fig. 7b, e, insets). Figure 7e (inset, arrow) shows a negative 


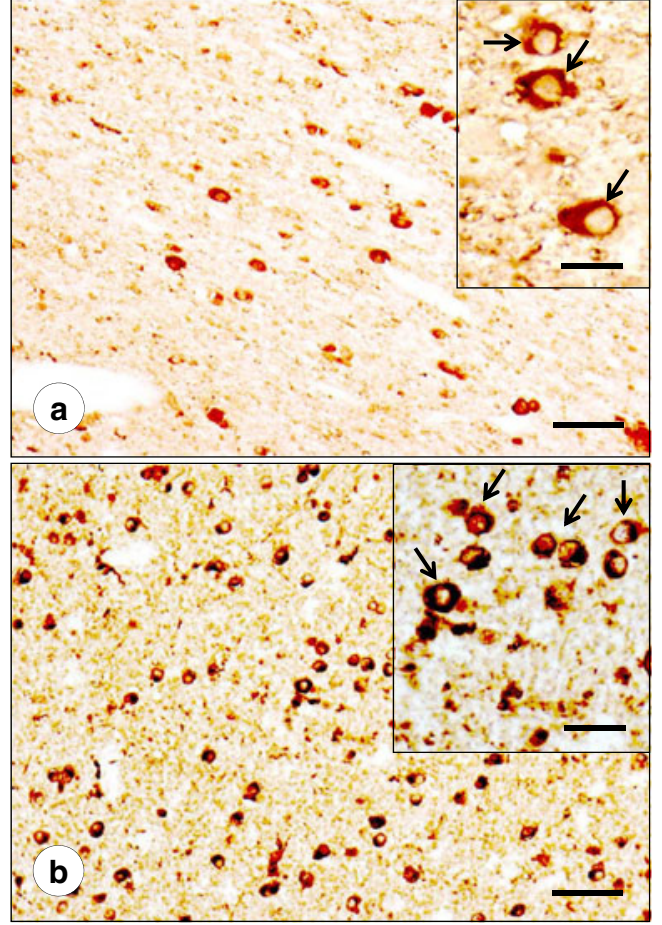

Fig. 6 Ferritin immunohistochemistry of hilar white matter of the DN. a Normal control; b FRDA (case FRDA1, $M$ in Table 1). In the normal hilar white matter, ferritin-positive cells are consistent with oligodendroglia (arrows in a, inset). Ferritin reaction product also labels oligodendroglia in the DN white matter of FRDA (b), but their density per unit area is higher, and their size is smaller (arrows in b, inset). Bars: a, b $50 \mu \mathrm{m}$; (a and b insets), $20 \mu \mathrm{m}$

white matter, ATP7A reaction product is prominent in vessel walls. Strong immunoreactivity of choroid plexus epithelium in the same section serves as a positive control (Fig. 9a, inset). Higher vascularity of gray matter explains the greater number of reactive vessels in the $\mathrm{DN}$ ribbon than in the adjacent white matter, but there are no obvious differences between control and FRDA. Confocal fluorescence microscopy of sections doubly stained for ATP7A and carbohydrate chains (by TRITC-labeled RCA-1) confirms the localization of the copper-carrying protein in vessel walls. Reaction product of ATP7A occurs in small discontinuous packets with a diameter of less than $0.5 \mu \mathrm{m}$ (Fig. 9c, f).

Figure 10 illustrates the changes in MT-1/2 and MT- 3 in the DN due to FRDA. The green finely granular MT reaction products are consistent with localization in astrocytes and their processes. The MT-1/2- and MT-3-immunoreactive cytoplasm of astrocytic cell bodies is GFAP-negative, whereas processes display some co-localization. In FRDA, fibrous gliosis is evident by red GFAP fluorescence (Fig. 10c, d). MT-1/2 and MT-3 fluorescence contributes to DN gliosis in FRDA by an abundance of delicate processes, but the disease does not cause a greater degree of co-expression of GFAP and the metallothioneins in comparison with the normal state.

\section{Discussion}

Application of XRF to Metal Measurements in Tissue Volumes

The XRF unit was originally developed for surface analysis [16-18], but the introduction of homogeneous metal standards (Fig. 1) now allows measurements based on volume. PEG has unusual properties when mixed with aqueous solutions due to its amphipathic nature [19]. Inorganic salts of Fe, $\mathrm{Cu}$, and $\mathrm{Zn}$ are unsuitable for the development of metal standards, but Fe-III-, Cu-II-, and Zn-II-mesoporphyrins dissolve readily in liquefied PEG/DMSO. Progressive infiltration of fixed tissue samples by PEG/DMSO at $60^{\circ} \mathrm{C}$ displaces all tissue water, and XRF signals can be used to quantify $\mathrm{Fe}, \mathrm{Cu}$, and $\mathrm{Zn}$ in terms of micrograms per milliliter. Due to high water content of brain tissue, the results of this study approximate previous data on these metals in tissue samples that were expressed as micrograms per gram wet or dry weight [6-9].

Metal maps and quantification by XRF provide a major advantage over assays of tissue extracts. The method shows metal concentrations in situ and in context with the microscopic anatomy of the tissue. Metals in the DN are not homogeneously distributed and display nonidentical concentration gradients of $\mathrm{Fe}, \mathrm{Cu}$, and $\mathrm{Zn}$ (Fig. 2). Rapid processing after fixation is especially important for the study of $\mathrm{Zn}$ because this metal is subject to rapid redistribution due to autolysis [20]. To some degree, this artifact is also true for $\mathrm{Cu}$. Prolonged storage of cerebellar slices ultimately causes the disappearance of $\mathrm{Cu}$ and Zn from XRF maps, and three FRDA cases were rejected from further analysis. Persistence of $\mathrm{Fe}$ fluorescence even after extended storage in fixative is likely due to metal localization in the shell of holoferritin. In successfully processed control specimens (Fig. 2), $\mathrm{Cu}$ and $\mathrm{Zn}$ appear in comparable locations (Fig. 2b, c), presumably because these metals are normally present in neurons and terminals.

Persistence of $\mathrm{Fe}, \mathrm{Cu}$, and $\mathrm{Zn}$ in the DN of FRDA; and Increasing Admixture of $\mathrm{Fe}$ and $\mathrm{Cu}$

Friedreich's ataxia does not increase or decrease the net amounts of $\mathrm{Fe}, \mathrm{Cu}$, or $\mathrm{Zn}$ (Table 2). Koeppen et al. [4] assayed total $\mathrm{Fe}$ in digests of dissected $\mathrm{DN}$ and found values in FRDA that were in the normal range. Western blots, however, revealed a larger contribution of light (L) ferritin subunits to holoferritin, suggesting accelerated ferritin biosynthesis due to persistent excess of free Fe. Localization and persistence of $\mathrm{Fe}$ have clinical implications. Signal hypointensity on T2-weighted magnetic resonance images (MRI) in FRDA [21, 22] detects bulk Fe in DN white 


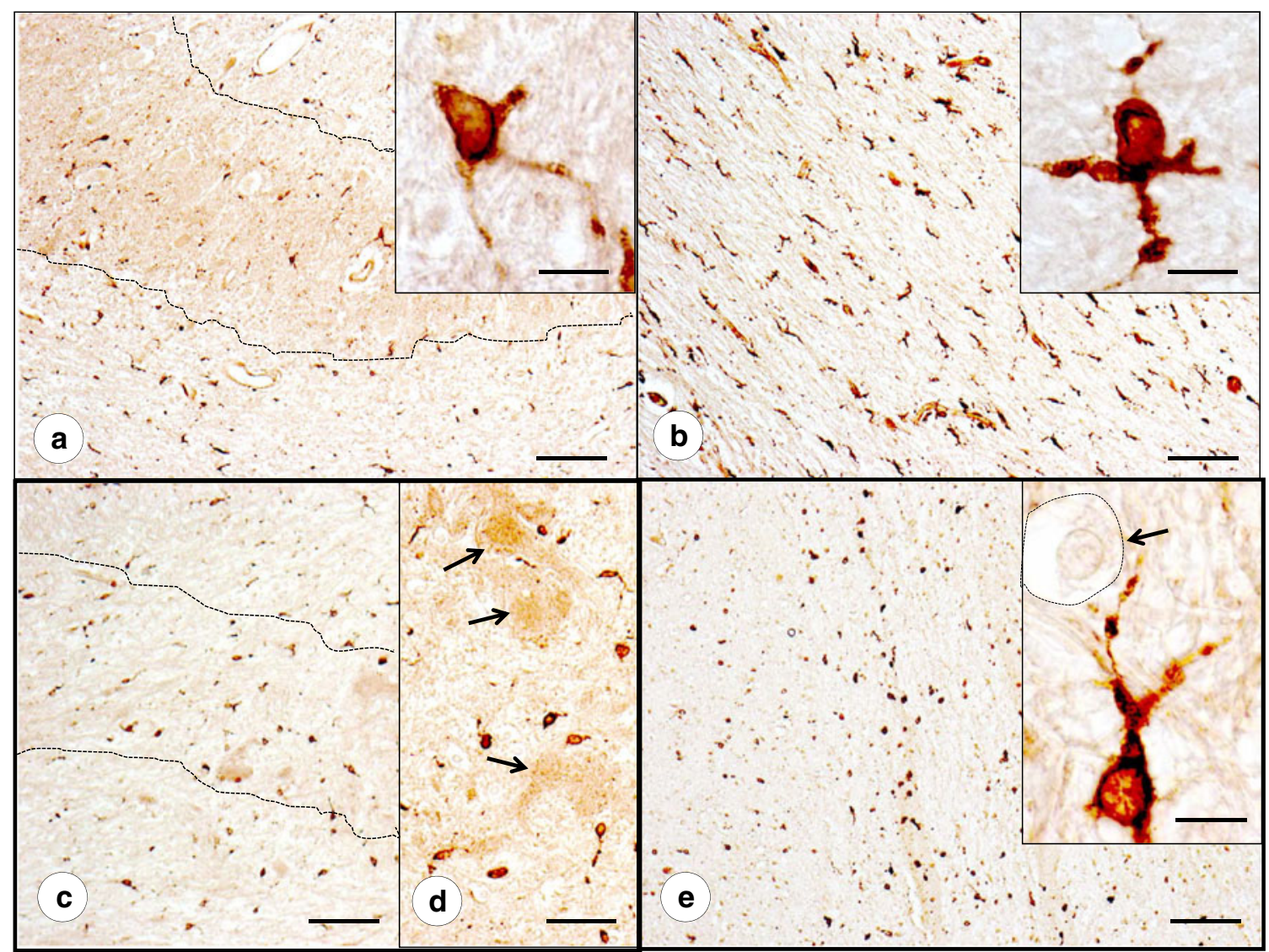

Fig. 7 SOD immunohistochemistry of $\mathrm{DN}$ gray and white matter. $\mathbf{a}, \mathbf{b}$, Normal control; c-e, FRDA (case FRDA8, M in Table 1); a, c-d Gray matter (DN outlined by interrupted lines); b, e White matter. The plump SOD-reactive cells with sparse processes are consistent with microglia (insets in $\mathbf{a}, \mathbf{b}$, and $\mathbf{e}$ ). These SOD-reactive cells are generally more frequent in the hilar white matter of the $\mathrm{DN}(\mathbf{b}, \mathbf{e})$ than in the DN gray matter $(\mathbf{a}, \mathbf{c})$. Abundance, size, and shape of SOD-reactive cells in
FRDA (c-e) do not differ from normal $(\mathbf{a}, \mathbf{b})$. SOD-reactive cells cluster around grumose degeneration in FRDA (arrows in d). The inset in e (arrow and interrupted line) shows a large SOD-negative oligodendrocyte in the immediate vicinity of a strongly SOD-reactive microglial cell. Bars: a-c and e $100 \mu \mathrm{m}$; insets in $\mathbf{a}, \mathbf{b}$, and $\mathbf{e} 10 \mu \mathrm{m}$ (oil immersion optics); d $50 \mu \mathrm{m}$ matter, and it is unlikely that the more diffuse distribution of $\mathrm{Cu}$ and $\mathrm{Zn}$ in FRDA has measurable effects on MRI signals. Routine MRI of the DN in FRDA at high magnetic field strengths is only now emerging, and none of the patients listed in Table 1 had targeted visualization of this gray matter structure. The DN pathology reported here represents the morphological end stage of FRDA. Death of an FRDA patient from cardiomyopathy before onset of ataxia is uncommon. In such cases, the DN may still be entirely normal [2].

The two outstanding abnormalities in the DN of FRDA are the persistence of $\mathrm{Fe}, \mathrm{Cu}$, and $\mathrm{Zn}$ in and about the $\mathrm{DN}$ and the increasing admixture of $\mathrm{Cu}, \mathrm{Zn}$, and $\mathrm{Fe}$ signals (Figs. 2 and 4). It is evident that destruction of DN neurons and synaptic terminals releases $\mathrm{Cu}$ and $\mathrm{Zn}$, which then diffuse into the neuropil and enter the adjacent $\mathrm{Fe}$ rich white matter. The clinical importance of adding $\mathrm{Cu}$ and $\mathrm{Zn}$ to the Fe-rich regions of the DN in FRDA is unknown. Though $\mathrm{Cu}$ ions may equal $\mathrm{Fe}$ ions in the ability to generate oxygen radicals $[23,24]$, the immunohistochemical observations provide no insight into potential oxidative damage induced by $\mathrm{Cu}$ or $\mathrm{Zn}$. Without an efficient local control mechanism, the endogenous $\mathrm{Cu}$ concentrations in the DN (12-33 $\mu \mathrm{g} / \mathrm{ml}$; Table 2) would be sufficient to cause tissue damage. The previously reported intracerebral injection of $\mathrm{Cu}$ sulfate at $0.5 \mu \mathrm{g} / 0.1 \mathrm{ml}$ [12], equaling $19.9 \mu \mathrm{g} / \mathrm{ml}$ of $\mathrm{Cu}$, causes necrosis [12], but this result is not directly comparable to endogenous $\mathrm{Cu}$ that is largely bound to proteins. Inorganic $\mathrm{Cu}[11,12]$ is known to be more toxic than $\mathrm{Cu}$ bound to proteins [13]. It is likely that the main form in the DN of FRDA is proteinbound $\mathrm{Cu}$.

\section{Correlation of XRF Maps and Histology}

Atrophy of the DN in FRDA, as shown by immunohistochemistry of NSE (Fig. 4d-f) and GAD (Fig. 4g-i), must be correlated with $\mathrm{Cu}$ and $\mathrm{Zn}$ redistribution rather than with $\mathrm{Fe}$ 
Fig. 8 Double-label immunofluorescence of the pairs SOD/ferritin and SOD/ CD68 in the DN of normal controls and two cases of FRDA. a-c, $\mathbf{g}-\mathbf{i}$ Normal controls; d-f FRDA (case FRDA8, $\mathrm{M}$ in Table 1); j-I FRDA (case FRDA2, $\mathrm{M}$ in Table 1); a, d SOD (FITC, green); b, e Ferritin (Cy3, red); c, f Merged images. $\mathbf{g}$, j SOD (Alexa488); h, k CD68 (Cy3); i, I merged images. SOD fluorescence in perikarya and proximal processes co-localizes with cytosolic ferritin $(\mathbf{c}, \mathbf{f})$. The SOD-immunoreactive cells also contain granular CD68 reaction product (i, l). In FRDA (k-l), CD68 reaction product is more abundant, suggesting microglial hypertrophy (see also Fig. 5c). Confocal microscopy at an optical slice thickness of $1 \mu \mathrm{m}$. Bars, $10 \mu \mathrm{m}$
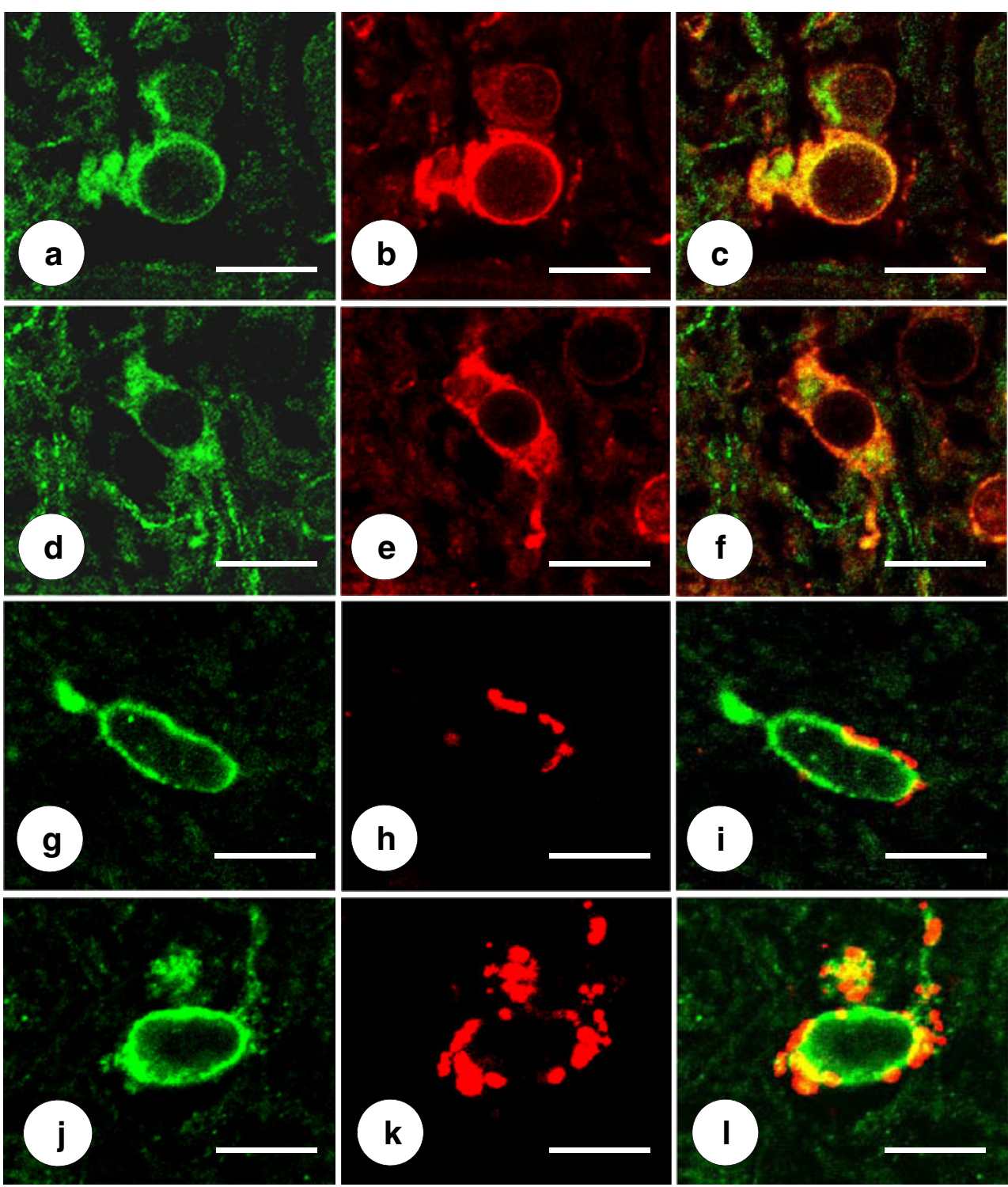

only. Despite its main localization in hilar white matter of the $\mathrm{DN}, \mathrm{Fe}$ in the gray matter ribbon is still substantially higher than the maximum $\mathrm{Cu}$ and $\mathrm{Zn}$ concentrations in the same location (Table 2). Therefore, Fe in the DN gray matter cannot be ignored, especially in light of frataxin loss in the DN of patients with FRDA [1]. Ferritin is a surrogate marker of disturbed Fe metabolism, but immunohistochemistry with anti-ferritin shows only modest changes in abundance and size of microglia in DN gray matter (Fig. 5c, d). Grumose degeneration appears to attract ferritin-positive microglia (Fig. 5d), and it is of interest that the abnormal clusters of GABA-ergic terminals also contain ferroportin [4]. It is evident that oligodendroglia in the DN hilus express ferritin constitutively, and crowding of small ferritin-containing cells in the central white matter of the DN may be a secondary event without relevance to the pathogenesis of FRDA (Fig. 6b).
Control Mechanisms of $\mathrm{Fe}, \mathrm{Cu}$, and $\mathrm{Zn}$ in FRDA

Findings illustrated in Figs. 5, 7, 8, and 10 suggest that the potentially toxic admixture of $\mathrm{Fe}$ and $\mathrm{Cu}$ in FRDA generates a defensive response in microglia and astrocytes. The universal reaction to surges in free $\mathrm{Fe}$ in mammalian tissues is the translational stimulation of ferritin biosynthesis through the interaction of iron-responsive elements in the 5 '-untranslated region of messenger ribonucleic acid and iron-regulatory proteins 1 and 2. Sequestration of ferric iron inside the shell of holoferritin is an efficient mechanism by which Fe-catalyzed generation of oxygen radicals is mitigated. The immediate defense against free or loosely bound brain $\mathrm{Fe}$ occurs in microglia. Juxtaneuronal cells in the DN (Fig. 5a) and oligodendroglia in the DN white matter (Fig. 6) may involve a ferritin receptor [25], but the response of these cells to the FRDA disease process 


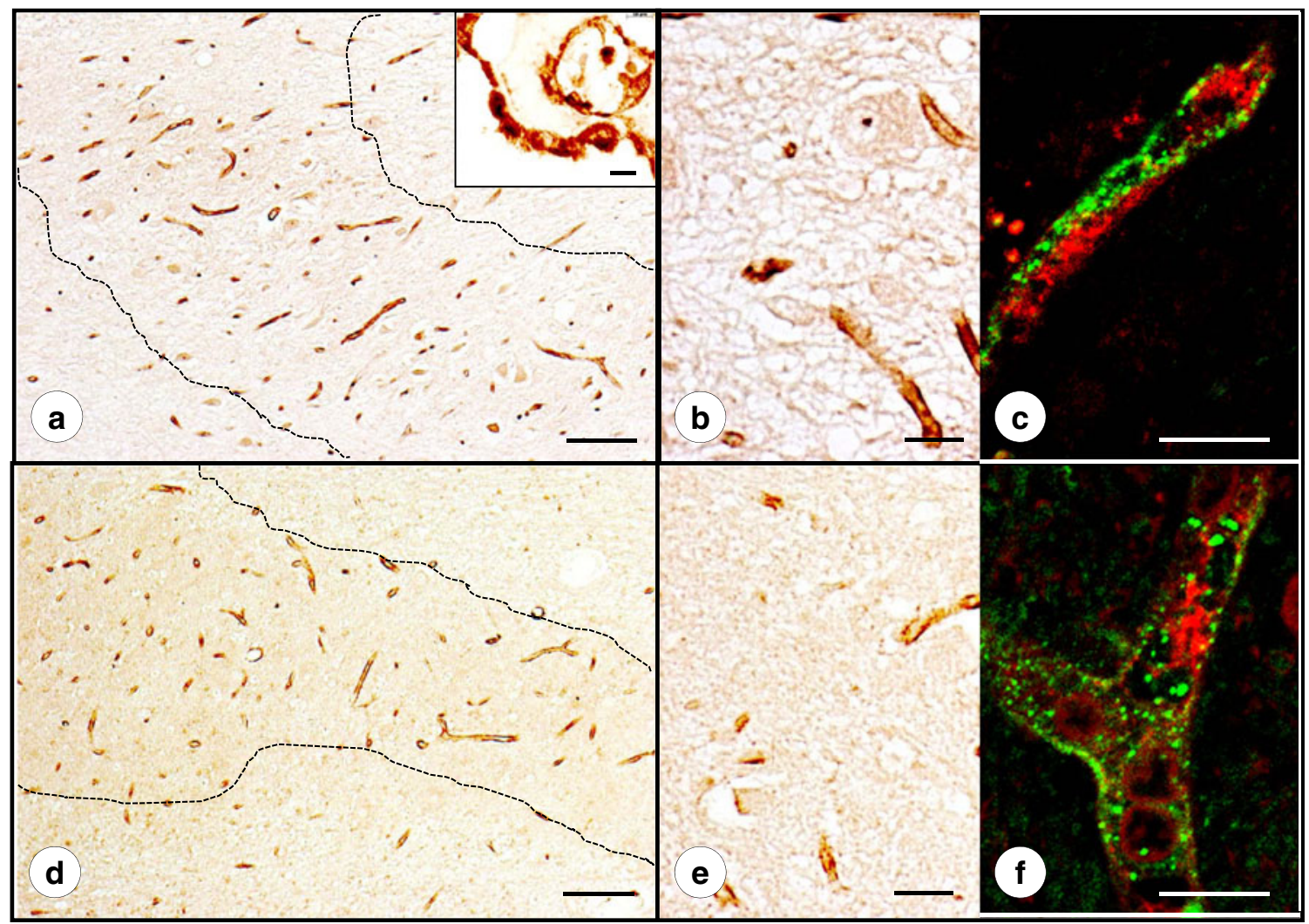

Fig. 9 ATP7A immunohistochemistry and immunofluorescence of the DN in a normal control and FRDA. a-c Normal control; d-f FRDA (case FRDA2, $\mathrm{M}$ in Table 1). In a and $\mathbf{d}$, the approximate boundaries of the DN gray matter are outlined by interrupted lines. Positive-contrast reaction product labels capillary walls that are much more abundant in the DN neuropil than in the white matter of hilus or fleece, reflecting the generally higher vascularity of gray matter. FRDA (d-f) does not differ from the control $(\mathbf{a}-\mathbf{c})$. The inset in a shows reaction product in epithelial cells of the choroid plexus on the same slide, serving as an internal positive control. Higher power resolution (b and e) shows the granular nature of ATP7A reaction product in vessel walls, which is more apparent on double-label fluorescence of ATP7A (FITC, green) and RCA-1 (TRITC, red) (c and f). Fluorescent reaction product of ATP7A is present in granules or vesicles with a diameter of less than $0.5 \mu \mathrm{m}$ and does not occur uniformly in all areas of the vessel wall. Confocal microscopy at an optical slice thickness of $1 \mu \mathrm{m}$. Bars: a, d $100 \mu \mathrm{m} ; \mathbf{b}, \mathbf{e}$, and inset in a $20 \mu \mathrm{m} ; \mathbf{c}, \mathbf{f} 10 \mu \mathrm{m}$ appears limited in comparison with gray matter microglia (Fig. 5c, d).

The potential endogenous excess of $\mathrm{Cu}$ and $\mathrm{Zn}$ in FRDA is limited to the $\mathrm{DN}$ and occurs over many years during the course of the patient's illness. While $\mathrm{Cu}$ and $\mathrm{Zn}$ dysmetabolism can probably not be measured by attention to a single $\mathrm{Cu}-$ or $\mathrm{Zn}$-responsive protein in analogy to ferritin, SOD, ATP7A, and the metallothionein isoproteins are promising candidates [26]. More is known about brain $\mathrm{Cu}$ control than about the fate of cerebral $\mathrm{Zn}$ (20). Brain $\mathrm{Cu}$ turnover in adult rats is extremely slow [27], and retention of the metal in the DN of patients with FRDA is not surprising. The mechanism of this $\mathrm{Cu}$ conservation is not known. Insight into cerebral $\mathrm{Cu}$ homeostasis is largely based on experimental $\mathrm{Cu}$ deficiency rather than excess $[28,29]$. Extracerebral organs respond to $\mathrm{Cu}$ deficiency by reduced SOD levels that reflect a posttranscriptional mechanism. Brain SOD activity and protein levels in adult rats do not decline despite a significant reduction in $\mathrm{Cu}$ concentration [28]. $\mathrm{Cu}$ incorporation into SOD relies on a copper chaperone for SOD (CCS). It is expressed in brain and increases in response to lowered brain $\mathrm{Cu}$ levels [30]. Peculiarly, the lack of CCS in genetically modified mice causes severely lowered levels of brain $\mathrm{Cu}$, SOD protein, and SOD activity [30]. Therefore, it may be assumed that $\mathrm{Cu}$ homeostasis in the normal human DN also involves CCS-SOD interaction [31], but a role of these proteins in the $\mathrm{Cu}$ redistribution in the DN of FRDA patients remains to be established.

Immunohistochemistry and immunofluorescence of SOD and ATP7A (Figs. 7, 8, and 9) provide only inconclusive evidence that the FRDA-damaged DN undergoes changes due to $\mathrm{Cu}$ excess. Clustering of SOD-positive cells about regions of grumose degeneration (Fig. 7d) suggests a response to $\mathrm{Cu}$ release from corticonuclear terminals. The presence of SOD reaction product in microglia, as shown in Figs. 7 and 8, is at variance with the neuronal localization in the human CNS reported by others [32]. Positive-contrast and immunofluorescent reaction products suggest that $\mathrm{Cu}$ bound to SOD and Fe sequestered in holoferritin share the 
Fig. 10 Double-label immunofluorescence of MT-1/ 2, MT-3, and GFAP in the DN. a, b Normal control; c, d FRDA (FRDA8, $\mathrm{M}$ in Table 1); a, c MT-1/2; b, d MT-3. The MTs are shown by green fluorescence, GFAP by red fluorescence. Neuronal loss in FRDA (c) and (d) is apparent by the absence of nerve cell voids $(N)$. MT-1/2 and MT-3-containing astrocytic cell bodies show no GFAP reaction product. Only a few glial processes display colocalization of MT-1/2 and GFAP $(\mathbf{a}, \mathbf{c})$ or MT-3 and GFAP (b, d). In FRDA, both MT-1/2 and MT-3 show a greater abundance of finely granular green reaction product. Confocal microscopy at an optical slice thickness of $1 \mu \mathrm{m}$. Bars, $20 \mu \mathrm{m}$
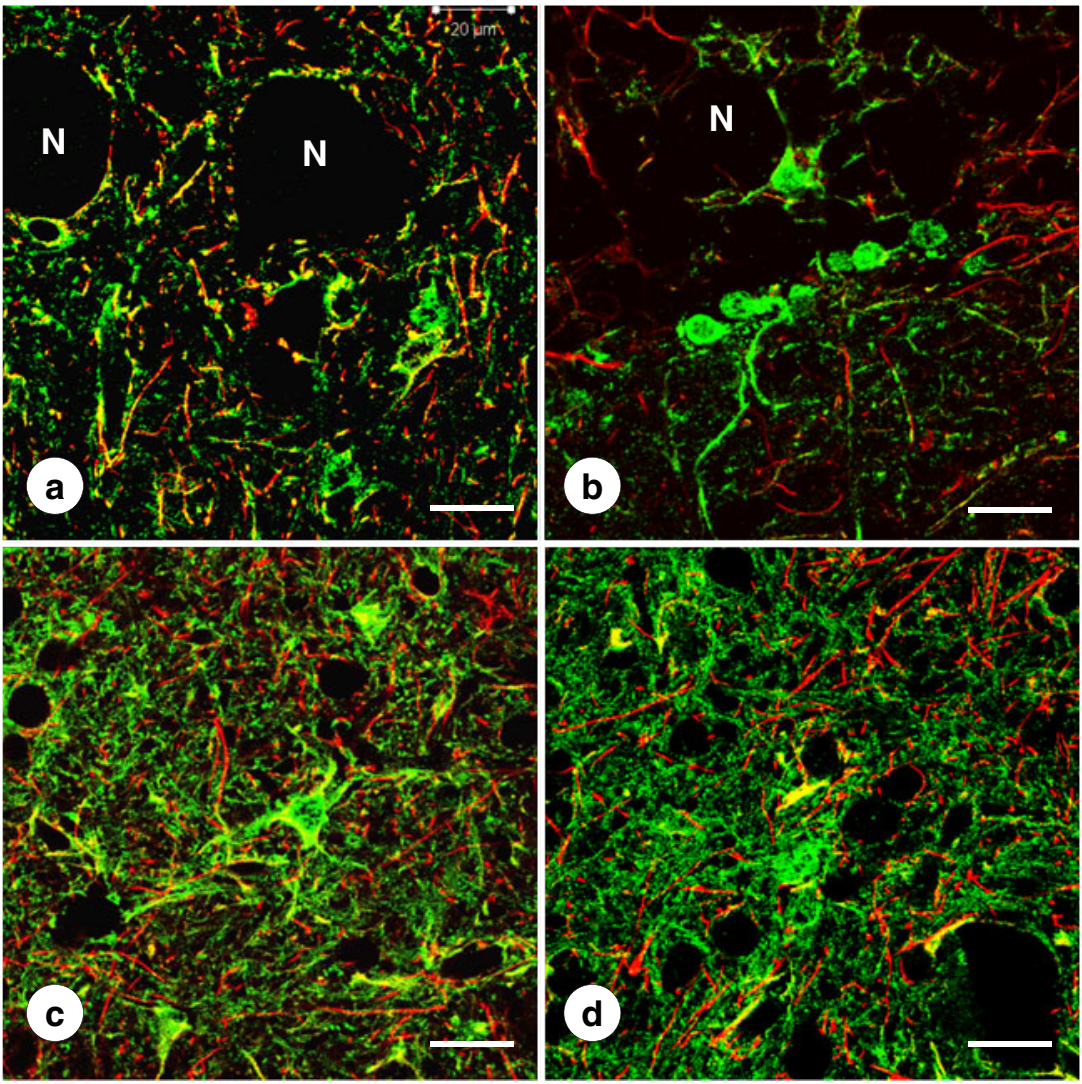

same localization (Fig. 8). It may be reasonable to propose that SOD activity and Fe sequestration in holoferritin provide an efficient antioxidant mechanism in microglia. Granular ATP7A fluorescence in vessel walls (Fig. 9c, f) is consistent with vesicular trafficking between the transGolgi network and the plasma membrane [33], including endothelial cells $[34,35]$. ATP7A primarily serves $\mathrm{Cu}$ uptake [34, 35] rather than the return of the metal to the bloodstream. Figure 9 suggests that the mechanism of $\mathrm{Cu}$ uptake in the DN of FRDA remains unchanged.

Metallothionein immunohistochemistry has been used to detect a biological response to $\mathrm{Cu}$ excess in the brain [36], though the experiments were unusual. Sheep were first $\mathrm{Cu}$-fed and then treated over a period of time with the $\mathrm{Cu}$-chelator ammonium tetrathiomolybdate. The $\mathrm{Cu}$-chelator complex entered the brain and raised total $\mathrm{Cu}$ in selected regions three- to four-fold. The steepest increase occurred in cerebellum (from 16.7 to $60.8 \mu \mathrm{g} / \mathrm{g}$ ). While this $\mathrm{Cu}$ excess caused no neuronal damage, it strongly stimulated expression of metallothioneins in astroglia, as shown by immunohistochemistry with an antibody to MT1 and MT2. It is generally accepted that astrocytes strongly express MT-1/2 and MT-3 [37]. Blaauwgeers et al. [38] reported that the cellular localizations of MT and GFAP in normal human brain are mutually exclusive, implying MT expression in a subset of astrocytes. The observations shown here (Fig. 10) are consistent with this interpretation. It may also be important that DN gliosis in FRDA did not change the relative abundance of GFAP and MT-1/2 or MT-3 proteins (Fig.10). MT occurs in at least four isoforms that respond to several metals other than $\mathrm{Cu}$ and $\mathrm{Zn}$ and to various nonmetal stimuli. The observations illustrated in Fig. 10c, d do not prove that an excess of $\mathrm{Cu}, \mathrm{Zn}$, or both cause the greater abundance of MT-positive fibers in FRDA. Upregulation of brain MT occurs in disorders that are not obviously related to metals [37], and caution is necessary in the interpretation of increased MT reaction product in the DN of FRDA. Nevertheless, the participation of MT-1/2 and MT-3 in the glial response to FRDA that is independent of GFAP expression indicates an intact biochemical and cellular machinery for $\mathrm{Cu}$ and $\mathrm{Zn}$ detoxification. It cannot be assumed, however, that $\mathrm{Cu}$ and $\mathrm{Zn}$ remain innocuous through the course of the patient's illness. Protein analysis by Western blot may be a more informative method to detect changes in SOD, ATP7A, CCS, and the metallothioneins.

\section{$\mathrm{Fe}$ and $\mathrm{Cu}$ in Other Diseases of the DN}

Redistribution of $\mathrm{Fe}$ and $\mathrm{Cu}$ in the $\mathrm{DN}$ nucleus is not unique to FRDA. Among the hereditary ataxias, spinocerebellar ataxia type 3 is of immediate interest because neuronal loss, survival of small neurons, and grumose degeneration of the DN and integrity of the inferior olivary nuclei are similar to FRDA. In two suitable cases, XRF showed a similar collapse of the DN and merging of 
$\mathrm{Fe}, \mathrm{Cu}$, and $\mathrm{Zn}$ signals. Grumose degeneration, loss of large neurons, and preservation of small nerve cells also occur in the DN of progressive supranuclear palsy (PSP). XRF mapping of five specimens of PSP showed no $\mathrm{Cu}$ or $\mathrm{Zn}$ signals due to prolonged storage in fixative. The distribution of $\mathrm{Fe}$, however, displayed collapse of the $\mathrm{DN}$ and retention of maximum $\mathrm{Fe}$ XRF in the hilus of the nucleus that strongly resembled FRDA.

\section{A Rationale for Therapy of FRDA Based on Insights} into Metal Dysmetabolism

The "intimate relationship" of $\mathrm{Fe}$ and $\mathrm{Cu}$ metabolism [39] is likely as true for the central nervous system as it is for other organs and offers new research avenues in FRDA and for therapeutic approaches. Beyond a direct damaging effect of free $\mathrm{Cu}$ on the tissues of the $\mathrm{DN}$, it is also possible that metal impacts the fate of $\mathrm{Fe}$ in the same location. Measuring $\mathrm{Fe}$ - and $\mathrm{Cu}$-mediated oxidative damage to the neurons of the $\mathrm{DN}$ in human autopsy tissues remains a challenge. There is little doubt that atrophy of large DN neurons is primary [2] but the precise mechanism of their selective destruction remains elusive. Chelation therapy to remove $\mathrm{Fe}$ [21] and possibly $\mathrm{Cu}$ [40] may protect these cells against downstream damage. Study of the surviving small neurons [2] may offer additional insight into the pathogenesis of the DN lesion in FRDA. Small nerve cells in the DN are heterogeneous and not exclusively GABA-ergic. In rodents, some of the smaller neurons of the cerebellar nuclei are glycinergic [41] or use other transmitters in their connections. FRDA does not affect the GABA-ergic dentato-olivary tract in humans [2], but the fate of small nonGABA-ergic neurons is unknown. Small neurons in the DN may have an intrinsic resistance to frataxin deficiency or tolerance to local $\mathrm{Cu}$ and $\mathrm{Zn}$ excess.

A possible therapy to mitigate $\mathrm{Cu}$ toxicity to the $\mathrm{DN}$ is the systemic administration of pregabalin [42]. Marmolino and Manto [42] delivered small amounts of free $\mathrm{Cu}$ into the nucleus interpositus of rats by reverse microdialysis. The animals showed increased excitability of the contralateral motor cortex that could be inhibited by pretreatment with pregabalin. The experiments addressed the functional consequences of local $\mathrm{Cu}$ excess and differed from previous studies that only sought to determine the necrotizing effects of $\mathrm{Cu}$ on brain tissue $[11,12]$. Delivery of small amounts of $\mathrm{Cu}$ into cerebellar nuclei is not directly comparable to the slow redistribution of $\mathrm{Cu}$ in the human DN during FRDA, but the results still provide a reasonable rationale for a clinical trial with pregabalin.

Acknowledgments Dr. Koeppen receives financial support from the National Institutes of Health (R01 NS069454-02); Friedreich's Ataxia Research Alliance; National Ataxia Foundation; and Neurochemical Research, Inc. The XRF unit was conceived and constructed by the staff of X-Ray Optical Systems, East Greenbush, NY, USA, with support from the National Institutes of Health (5R44R022001-03). This work was performed in the research laboratories of the Veterans Affairs Medical Center, Albany, NY, USA. Dr. Joseph R. Prohaska, Duluth, MN, USA, advised the authors on brain $\mathrm{Cu}$ metabolism. Dr. Stephen G. Kaler, National Institutes of Health, Bethesda, MD, USA, reviewed the manuscript and advised the authors on the biology of ATP7A. He also provided an alternate antibody to ATP7A. Dr. Dennis Dickson, Mayo Clinic, Jacksonville, FL, provided the specimens of progressive supranuclear palsy.

Conflict of interest The authors acknowledge no conflict of interest.

Open Access This article is distributed under the terms of the Creative Commons Attribution License which permits any use, distribution, and reproduction in any medium, provided the original author(s) and the source are credited.

\section{References}

1. Koeppen AH. Friedreich's ataxia: pathology, pathogenesis, and molecular genetics. J Neurol Sci. 2011;303:1-12.

2. Koeppen AH, Davis AN, Morral JA. The cerebellar component of Friedreich's ataxia. Acta Neuropathol. 2011;122:323-30.

3. Koeppen AH, Dickson AC, Lamarche JB, Robitaille Y. Synapses in the hereditary ataxias. J Neuropathol Exp Neurol. 1999;58:748-64.

4. Koeppen AH, Michael SC, Knutson MD, Haile DJ, Qian J, Levi S, et al. The dentate nucleus in Friedreich's ataxia: the role of iron responsive proteins. Acta Neuropathol. 2007;114:163-73.

5. Bayot A, Santos R, Camadro J-M, Rustin P. Friedreich ataxia: the vicious circle hypothesis revisited. BMC Med. 2011. doi:10.1186/ 1741-7015-9-112.

6. Warren PJ, Earl CJ, Thompson RHS. The distribution of copper in human brain. Brain. 1960;83:709-17.

7. Ule G, Völkl A, Berlet H. Spurenelemente im menschlichen Gehirn. Z Neurol. 1974;206:117-28.

8. Höck A, Demmel U, Schicha H, Kasperek K, Feinendegen LE. Trace element concentration in human brain. Brain. 1975;98:49-64.

9. Duflou H, Maenhaut W, De Reuck J. Regional distribution of potassium, calcium, and six trace elements in normal human brain. Neurochem Res. 1989;14:1099-112.

10. Popescu BFG, Robinson CA, Rajput A, Rajput AH, Harder SL, Nichol H. Iron, copper, and zinc distribution of the cerebellum. Cerebellum. 2009;8:74-9.

11. Vogel FS, Evans JW. Morphological alterations produced by copper in neural tissues with consideration of the role of the metal in the pathogenesis of Wilson's disease. J Exp Med. 1961;113:9971004.

12. Wisniewski H, Majdecki T, Wisniewska K. Topography of brain lesions after intracerebral, intraventricular and subarachnoid injection of copper salts. Neuropatol Polska. 1965;3:391-6.

13. Lem KE, Brinster LR, Tjurmina O, Lizak M, Lal S, Centeno JA, et al. Safety of intracerebroventricular copper histidine in adult rats. Mol Genet Metab. 2007;91:30-6.

14. Koeppen AH, Michael SC, Li D, Chen Z, Cusack MJ, Gibson $\mathrm{WM}$, et al. The pathology of superficial siderosis of the central nervous system. Acta Neuropathol. 2008;116:371-82.

15. Koeppen AH, Morral JA, Davis AN, Qian J, Petrocine SV, Knutson $\mathrm{MD}$, et al. The dorsal root ganglion in Friedreich's ataxia. Acta Neuropathol. 2009;118:763-76.

16. Chen ZW, Gibson WM, Huang H. High-definition X-ray fluorescence: principles and techniques. X-Ray Opt Instrum. 2008. doi: $10.1155 / 2008 / 318171$. 
17. Gibson WM, Chen ZW, Li D. High definition X-ray fluorescence: applications. X-Ray Opt Instrum. 2008. doi:10.1155/2008/709692.

18. Chen ZW, Wittry DW. Microanalysis by monochromatic microprobe X-ray fluorescence- physical basis, properties and future prospects. J Appl Phys. 1998;84:1064-73.

19. Chen J, Spear SK, Huddleston JG, Rogers RD. Polyethylene glycol and solutions of polyethylene glycol as green reaction media. Green Chem. 2005;7:64-82.

20. Frederickson CJ, Suh SW, Silva D, Frederickson CJ, Thompson RB. Importance of zinc in the central nervous system: the zinccontaining neuron. J Nutr. 2000;130:1471S-83S.

21. Boddaert N, Le Quan Sang KH, Rötig A, Leroy-Willig A, Gallet S, Brunelle F, et al. Selective iron chelation in Friedreich ataxia: biologic and clinical implications. Blood. 2007;110:401-8.

22. Waldvogel D, van Gelderen P, Hallett M. Increased iron in the dentate nucleus of patients with Friedreich's ataxia. Ann Neurol. 1999;46:123-5.

23. Halliwell B, Gutteridge JM. Role of free radicals and catalytic metal ions in human disease: an overview. Methods Enzymol. 1990;186:1-85.

24. Koppenol WH. Chemistry of iron and copper in radical reactions. In: Rice-Evans CA, Burdon RH, editors. Free radical damage and its control. Amsterdam: Elsevier; 1994. p. 3-24.

25. Todorich B, Pasquini JM, Garcia CI, Paez PM, Connor JR. Oligodendrocytes and myelination: the role of iron. Glia. 2009;57:467-78.

26. Prohaska JR, Gybina AA. Intracellular copper transport in mammals. J Nutr. 2004;134:1003-6.

27. Levenson CW, Janghobaini M. Long-term measurements of organ copper turnover in rats by continuous feeding of a stable isotope. Anal Biochem. 1994;221:243-9.

28. Prohaska JR, Brokate B. Lower copper, zinc-superoxide dismutase protein but not mRNA in organs of copper-deficient rats. Arch Biochem Biophys. 2001;393:170-6.

29. Prohaska JR, Broderius M, Brokate B. Metallochaperone for $\mathrm{Cu}$, $\mathrm{Zn}$-superoxide dismutase (CCS) protein but not mRNA is higher in organs from copper deficient mice and rats. Arch Biochem Biophys. 2003;417:227-34.

30. Prohaska JR, Geissler J, Brokate B, Broderius M. Copper, zinc-superoxide dismutase protein but not mRNA is lower in copper-deficient mice and mice lacking the copper chaperone for superoxide dismutase. Exp Biol Med. 2003;228:959-66.

31. Caruano-Yzermans AL, Bartnikas TB, Gitlin JD. Mechanism of the copper-dependent turnover of the copper chaperone for superoxide dismutase. J Biol Chem. 2006;281:13581-7.

32. Prado CA, Xu Z, Borchelt DR, Price DL, Sisoda SS, Cleveland DW. Superoxide dismutase is an abundant component in cell bodies, dendrites, and axons of motor neurons and in a subset of other neurons. Proc Natl Acad Sci USA. 1995;92:954-8.

33. Petris MJ, Mercer JFB, Culvenor JG, Lockhart P, Gleeson PA, Camakaris J. Ligand-regulated transport of the Menkes copper Ptype ATPase efflux pump from the Golgi apparatus to the plasma membrane: a novel mechanism of regulated trafficking. EMBO J. 1996;15:6084-95.

34. Choi B-S, Zheng W. Copper transport to the brain by the bloodbrain barrier and blood-CSF barrier. Brain Res. 2009;1248:14-21.

35. Qian Y, Tiffany-Castiglioni E, Welsh J, Harris ED. Copper efflux from murine microvascular cells requires expression of the Menkes disease Cu-ATPase. J Nutr. 1998;128:1276-82.

36. Dincer Z, Haywood S, Jasani B. Immunocytochemical detection of metallothionein (MT1 and MT2) in copper-enhanced sheep brains. J Comp Pathol. 1999;120:29-37.

37. Hidalgo J, Aschner M, Zatta P, Vasák M. Roles of the metallothionein family of proteins in the central nervous system. Brain Res Bull. 2001;55:133-45.

38. Blaauwgeers HGT, Sillevis Smitt PAE, De Jong JMBV, Troost D. Distribution of metallothionein in the human central nervous system. Glia. 1993;8:62-70.

39. Fox PL. The copper-iron chronicles: the story of an intimate relationship. BioMetals. 2003;16:9-40.

40. Alvarez HM, Xue Y, Robinson CD, Canalizo-Hernández MA, Marvin RG, Kelly RA, et al. Tetrathiomolybdate inhibits copper trafficking proteins through metal cluster formation. Science. 2010;327:331-4.

41. Uusisaari M, Knöpfel T. Functional classification of neurons in the mouse lateral cerebellar nuclei. Cerebellum. 2011;10:637-46.

42. Marmolino D, Manto M. Pregabalin antagonizes copperinduced toxicity in the brain: in vitro and in vivo studies. Neurosignals. 2010;18:210-22. 